\title{
Sak1 kinase interacts with Pso2 nuclease in response to DNA damage induced by interstrand crosslink-inducing agents in Saccharomyces cerevisiae
}

\author{
Fernanda M. Munari ${ }^{\mathrm{a}, 1}$, Luis F. Revers ${ }^{\mathrm{a}, 1,2}$, Jacqueline M. Cardone ${ }^{\mathrm{a}, 3}$, Bruna F. Immich ${ }^{\mathrm{a}, \mathrm{d}}$, Dinara J. Moura ${ }^{\mathrm{d}}$, \\ Temenouga N. Guecheva a,b ${ }^{\mathrm{a}}$, Diego Bonatto ${ }^{\mathrm{a}}$, Jomar P. Laurino ${ }^{\mathrm{e}}$, Jenifer Saffi ${ }^{\mathrm{d}}$, Martin Brendel ${ }^{\mathrm{c}}$, \\ João A.P. Henriques ${ }^{a, b, e, *}$ \\ a Biotechnology Center, Federal University of Rio Grande do Sul (UFRGS), 91507-970 Porto Alegre, RS, Brazil \\ ${ }^{\mathrm{b}}$ Department of Biophysics, Federal University of Rio Grande do Sul (UFRGS), 91507-970 Porto Alegre, RS, Brazil \\ ${ }^{c}$ Department of Biological Sciences, State University of Santa Cruz (UESC), 45662-900 Ilhéus, BA, Brazil \\ ${ }^{\mathrm{d}}$ Federal University of Health Sciences of Porto Alegre (UFCSPA), 90050-170 Porto Alegre, RS, Brazil \\ e Biotechnology Institute, University of Caxias do Sul (UCS), 95070-560 Caxias do Sul, RS, Brazil
}

\section{A R T I C L E I N F O}

\section{Article history:}

Received 15 October 2012

Received in revised form 20 November 2013

Accepted 27 November 2013

Available online 4 December 2013

\section{Keywords:}

DNA repair

Interstrand cross-link

Two Hybrid System

SAK1/PAK1

PSO2/SNM1

MRX complex

\begin{abstract}
A B S T R A C T
By isolating putative binding partners through the two-hybrid system (THS) we further extended the characterization of the specific interstrand cross-link (ICL) repair gene PSO2 of Saccharomyces cerevisiae. Nine fusion protein products were isolated for Pso2p using THS, among them the Sak1 kinase, which interacted with the C-terminal $\beta$-CASP domain of Pso2p. Comparison of mutagen-sensitivity phenotypes of pso2 $\Delta$, sak $1 \Delta$ and pso2 $\Delta s a k 1 \Delta$ disruptants revealed that SAK1 is necessary for complete WT-like repair. The epistatic interaction of both mutant alleles suggests that Sak1p and Pso2p act in the same pathway of controlling sensitivity to DNA-damaging agents. We also observed that Pso2p is phosphorylated by Sak1 kinase in vitro and co-immunoprecipitates with Sak1p after 8-MOP+UVA treatment. Survival data after treatment of pso2 $\Delta, y k u 70 \Delta$ and $y k u 70 \Delta p s o 2 \Delta$ with nitrogen mustard, PSO2 and SAK1 with YKU70 or DNL4 single-, double- and triple mutants with 8-MOP+UVA indicated that ICL repair is independent of YKu70p and DNL4p in S. cerevisiae. Furthermore, a non-epistatic interaction was observed between MRE11, PSO2 and SAK1 genes after ICL induction, indicating that their encoded proteins act on the same substrate, but in distinct repair pathways. In contrast, an epistatic interaction was observed for PSO2 and RAD52, PSO2 and RAD50, PSO2 and XRS2 genes in 8-MOP+UVA treated exponentially growing cells.
\end{abstract}

(ㄷ) 2013 Elsevier B.V. All rights reserved.

\section{Introduction}

DNA interstrand cross-links (ICLs) are extremely genotoxic lesions since they covalently link the two complementary DNA strands, thereby resulting in stalled transcription and DNA replication, and ultimately prevent segregation of chromosomes. ICLs can arise from reactions with endogenous chemicals, such as the lipid peroxidation product malondialdehyde, or from exposure to various clinical anti-tumor drugs (e.g., cisplatin, nitrosoureas,

\footnotetext{
* Corresponding author. Address: Universidade Federal do Rio Grande do Sul (UFRGS) - Centro de Biotecnologia, Av. Bento Gonçalves, 9500, Prédio 43421, Campus do Vale, Caixa Postal 15005, 91501-970 Porto Alegre, RS, Brazil. Tel.: +55 51 3308 6069; fax: +55 5133086084 .

E-mail address: pegas@cbiot.ufrgs.br (J.A.P. Henriques).

1 These authors contributed equally to this work.

2 Present address: EMBRAPA, National Research Center of Grape and Wine, 95700000 Bento Gonçalves, RS, Brazil.

3 Present address: Hospital de Clínicas de Porto Alegre - HCPA, 90035-903 Porto Alegre, RS, Brazil.
}

nitrogen mustards) and photo-therapy treatments (psoralen plus UVA light - PUVA therapy) [1,2]. The presence of one non-repaired ICL can be lethal in bacterial and yeast cells [1] and in mammalian cells 40 non-repaired ICLs induce cell death [3].

Yeast mutants cells hypersensitive to ICL-inducing agents were identified in the early 1980s by two independent genetic screenings in Saccharomyces cerevisiae, which showed sensitivity to photoactivated psoralen (PSO2) [4] and sensitivity to nitrogen mustard (SNM1) [5]. It was later demonstrated that these genes are allelic [6] and the nomenclature $\mathrm{PSO} 2$ was adopted to unify them [1]. pso2 yeast mutants have a unique feature, which is their hypersensitivity to photoactivated psoralen, bi- and polyfunctional alkylating compounds, while exhibiting only a wild-type (WT) level of sensitivity to monofunctional alkylating agents, ionizing radiation (IR), UVC light (254 nm) [7,8] and HO endonuclease [9].

The yeast gene PSO2 encodes a 76 kDa nuclear protein that is believed to belong to a small group of proteins acting predominantly during ICL repair (for a review, see Brendel et al. [10]). Pso2 yeast 
protein has DNA 5'-exonuclease activity [11] and an endonuclease activity specific for DNA hairpin opening [12]. This nuclease activity is conferred by the metallo- $\beta$-lactamase hydrolase together with the $\beta$-CASP (metallo- $\beta$-lactamase-associated CPSF Artemis SNM1/PSO2) domain $[13,14]$. The $\beta$-CASP domain consists of a conserved region in the C-terminal moiety that is unique to the PSO2 gene family and is predicted to be a nucleic acid binding domain $[11,13,15-17]$. The expression of yeast PSO2 mRNA is constitutively low, with approximately 0.3 transcripts/cell [18], but is induced about four times by ICL-inducing agents in exponentially growing cells [19]. Over-expression of PSO2 does not lead to an increased resistance to nitrogen mustard and cisplatin [20].

Five human orthologs for PSO2 were identified: SNM1A, SNM1B/ Apollo, and SNM1C/Artemis - which have roles in DNA metabolism and cell cycle regulation (reviewed by [14,21,22]; CPSF73 and ELAC2 - involved in RNA processing [15,21]. SNM1Ap is the functional mammal homolog of yeast Pso2p $[23,24]$ and has roles in mediating resistance to some cross-linking drugs and in the maintenance of genome stability following ICL formation. SNM1B/Apollo protein possesses a 5'-exonuclease activity and plays a role in telomere maintenance [16]. SNM1C/Artemis alone also has $5^{\prime}$-exonuclease activity, while the Artemis:DNA-PK complex endonucleolytically cleaves $5^{\prime}$ and $3^{\prime}$ overhangs and has hairpin-opening activity [25], acting in V(D)J recombination and immune competence; its deficiency results in a severe combined immunodeficiency, associated with increased cellular radio-sensitivity (RS-SCID) phenotype [26].

An intriguing aspect of ICL repair is that several DNA repair pathways have to work together in order to remove or bypass this lesion. In general terms, the pathways involved in ICL repair in $S$. cerevisiae are defined by homologous recombination (HR), translesion bypass synthesis (TLS) and nucleotide excision repair (NER) [8,9,27-29]. The involvement of Pso2 protein with these pathways still presents incompletely understood features. In yeast as in mammalian cells, cellular response to ICLs is cell cycle dependent [30]. The majority of ICLs are thought to be repaired during $S$ phase, when the collapse of a replication fork encountering an ICL triggers the repair machinery [30,31]. Indeed, an ICL-stalled replication fork results in the formation of a double strand break (DSB) that represents a severe damage to the cell [32] and must be properly repaired. In G1 phase, the ICL can be recognized by a stalled RNA polymerase during transcription or by NER factors [33], and an ICL processing pathway that includes NER and TLS was shown to predominate repair during this phase of the yeast cell cycle [29].

It is well-established that enzymes of NER start processing ICLcontaining DNA, but the repair process is post-incisionally blocked and DSBs are accumulated in absence of functional Pso2p, preventing the reconstitution of high molecular weight DNA in yeasts $[34,35]$. This points to a Pso2p function in ICL repair downstream of the incision event [9]. Moreover, the specific requirement for Pso2p in ICL repair suggests that DSBs formed during this process may be different from other forms of DNA breaks. Our bioinformatic analyses suggested Pso2p also to be a specific endonuclease related to the opening of hairpin structures that arise during DNA replication in the presence of ICLs [10] and, indeed, Pso2p was recently found to be a structure-specific DNA hairpin opening endonuclease, whose activity was required for repair of chromosomal breaks containing closed hairpin ends [12]. Thus, besides its $5^{\prime}-$ exonuclease function in DNA end resection [11], Pso2p may function in the processing of DNA ends to generate proper substrates for the repair process, as has already been proposed by other authors [34,36]. However, its precise function has remained elusive and there are still many aspects to be elucidated about Pso2p function in ICL repair.

The role of Pso2p in yeast ICL-repair could be better understood if its interaction with other proteins were known. Therefore, the aim of this study was to identify potential Pso2p binding partners using the yeast two-hybrid system (THS). Here we present a collection of potential binding partners of Pso2p and demonstrate in vitro that Pso2p is a phosphorylation target for protein kinase Sak1 (encoded by the open reading frame YER129w), a temperature-sensitive suppressor of DNA polymerase alpha (Pol $\alpha$ ) mutations [37] and also an activating kinase of the Snf1 protein under cellular stress conditions [38]. Furthermore, we show that Pso2p interacts epistatically with Sak1p after exposure to DNA-ICL inducing agents and that both proteins immunoprecipitate after 8-MOP photoaddition. Besides, survival assays in exponential cell growth revealed an epistatic interaction of PSO2 with XRS2, RAD50 and RAD52, while a non-epistatic interaction was observed with MRE11 gene and no interaction was detected with YKU70 and DNL4 genes in DNA-ICL containing yeast cells.

\section{Material and methods}

\subsection{Yeast strains and media}

The relevant genotypes of $S$. cerevisiae strains used in this study are listed in Table 1 . The mutants pso2 and sak1 isogenic with wildtype (WT) strain BY4742 were obtained by single step gene replacement [39] using pMS3141I vector containing the PSO2 coding ORF disrupted with URA3. The other mutants isogenic with WT strain BY4741 or BY4742 were constructed by disruption of PSO2, SAK1 or DNL4 genes by homologous recombination, using vector pGADT7 for amplification of pso2::LEU2, vector pEG202 for amplification of sak1::HIS3 and vector YCplac33 for amplification of dnl4::URA3 disruption cassettes, in accordance to Ausubel et al. [40]. The disruption cassettes were amplified with Platinum ${ }^{\circledR}$ high fidelity Taq DNA polymerase (Invitrogen) and the disruption confirmed by polymerase chain reaction (PCR). Primers are described in Table 2. Yeast strain EGY48 was kindly provided by Dr. R. Brent (Massachusetts General Hospital, Boston, MA, USA).

Yeast strains were grown in YPD medium (1\% yeast extract, $2 \%$ peptone, $2 \%$ glucose) at $30^{\circ} \mathrm{C}$. Auxotrophy and resistance markers were controlled on either synthetic medium - SynCo ( $0.67 \%$ yeast nitrogen base without amino acids, $2 \%$ glucose, $1 \%$ ammonium sulfate) supplemented with the appropriate amino acids and bases $(40 \mu \mathrm{g} / \mathrm{ml})$ or YPD plus geneticin (G418, Calbiochem) $0.2 \mathrm{mg} / \mathrm{ml}$, respectively. Plating medium was solidified with $2 \%$ agar.

\subsection{Escherichia coli strains and plasmids}

E. coli strains XL1-blue endA1 gyrA96(nal $\left.{ }^{\mathrm{R}}\right)$ thi-1 recA1 relA1 lac glnV44 $\mathrm{F}^{\prime}\left[:: \operatorname{Tn} 10 \operatorname{proAB}^{+} \operatorname{lacl}^{\mathrm{q}} \Delta(\mathrm{lacZ}) \mathrm{M} 15\right] \quad \operatorname{hsdR} 17\left(\mathrm{r}_{\mathrm{K}}^{-} \mathrm{m}_{\mathrm{K}}^{+}\right)$ (Stratagene), KC8 pyrF::Tn5, hsdR, leuB600, trpC9830, lac $\Delta 74$, strA, galK, hisB436 [41], and TOP10 [F-mcrA $\Delta$ (mrr-hsdRMS-mcrBC)

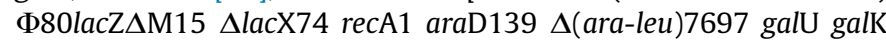
$\operatorname{rpsL}\left(\mathrm{Str}^{\mathrm{R}}\right)$ endA1 nupG] (Invitrogen) were used for plasmid manipulation and propagation. The following constructions were used: LexAPSO2-A (contains the PSO2 coding ORF from aa 47 to 661, in frame fused to the LexA DNA binding domain of pEG202 using an internal EcoRI restriction site); LexAPSO2-B (contains the PSO2 coding ORF from aa 47 to 466 , fused in frame to the LexA DNA binding domain of pEG202 via two internal EcoRI restriction sites). The first 46 triplets of $\mathrm{PSO} 2$ gene represent a non-transcribed region (GenBank accession number X64004) and were omitted from the plasmid. Techniques in yeast genetics and standard molecular techniques were performed according to Sambrook and Russell [42] and Burke et al. [43]. 
Table 1

Saccharomyces cerevisiae strains used in this study.

\begin{tabular}{|c|c|c|}
\hline Strain & Relevant genotype & Source \\
\hline BY4741 & MATa; his3 $\Delta 1$; leu $2 \Delta 0 ;$ ura3 $\Delta 0$; met $15 \Delta 0$ & Euroscarf \\
\hline aly24 & BY4742; with aly2::kanMX4 & Euroscarf \\
\hline yhr080c $\Delta$ & BY4742; with yhr080c::kanMX4 & Euroscarf \\
\hline EGY48 & MATa; ura3; his3; trp1; LexAOp(6)::LEU2 & R. Brent ${ }^{a}$ \\
\hline pso24 & BY4741; with pso2::LEU2 & This study \\
\hline $\operatorname{sak} 1 \Delta$ & BY4741; with sak1::HIS3 & This study \\
\hline pso2 $\Delta s a k 1 \Delta$ & BY4741; with pso2::LEU2; sak1::HIS3 & This study \\
\hline$y k u 704$ & BY4741; with $y k u 70:: k a n M X 4$ & Euroscarf \\
\hline$y k u 70 \Delta p s o 2 \Delta$ & BY4741; with yku70::kanMX4; pso2::LEU2 & This study \\
\hline$y k u 70 \Delta s a k 1 \Delta$ & BY4741; with $y k u 70:: k a n M X 4 ;$ sak1::HIS3 & This study \\
\hline yku70 $\Delta p s o 2 \Delta$ sak1 $\Delta$ & BY4741; with $y$ ku70::kanMX4; pso2::LEU2; sak1::HIS3 & This study \\
\hline $\operatorname{xrs} 24$ & BY4741; with xrs2::kanMX4 & Euroscarf \\
\hline$x r s 2 \Delta p s o 2 \Delta$ & BY4741; with xrs2::kanMX4; pso2::LEU2 & This study \\
\hline$x r s 2 \Delta s a k 1 \Delta$ & BY4741; with xrs2::kanMX4; sak1::HIS3 & This study \\
\hline$x r s 2 \Delta p s o 2 \Delta$ sak1 $\Delta$ & BY4741; with xrs2::kanMX4; pso2::LEU2; sak1::HIS3 & This study \\
\hline $\operatorname{dnl} 4 \Delta$ & BY4741; with dnl4::URA3 & This study \\
\hline dnl4 4 pso2 $\Delta$ & BY4741; with dnl4::URA3; pso2::LEU2 & This study \\
\hline 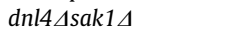 & BY4741; with dnl4::URA3; sak1::HIS3 & This study \\
\hline BY4742 & MAT $\alpha$; his $3 \Delta 1$; leu $2 \Delta 0 ;$ ura3 $\Delta 0 ;$ lys $2 \Delta 0$ & Euroscarf \\
\hline pso24 & BY4742; with pso2::URA3 & This study \\
\hline $\operatorname{sak} 1 \Delta$ & BY4742; with sak1::kanMX4 & Euroscarf \\
\hline pso2 $\Delta$ sak1 $1 \Delta$ & BY4742; with sak1::kanMX4; pso2::URA3 & This study \\
\hline mre11 14 & BY4742; with mre11::kanMX4 & Euroscarf \\
\hline mre11 1 pso2A & BY4742; with mre11::kanMX4; pso2::LEU2 & This study \\
\hline mre11 1 sak1 $\Delta$ & BY4742; with mre11::kanMX4; sak1::HIS3 & This study \\
\hline mre11 $\Delta$ pso2 $\Delta$ sak1 $\Delta$ & BY4742; with mre11::kanMX4; pso2::LEU2; sak1::HIS3 & This study \\
\hline $\operatorname{rad} 50 \Delta$ & BY4742; with rad50::kanMX4 & Euroscarf \\
\hline $\operatorname{rad} 50 \Delta p s o 2 \Delta$ & BY4742; with rad50::kanMX4; pso2::LEU2 & This study \\
\hline $\operatorname{rad} 50 \Delta s a k 1 \Delta$ & BY4742; with rad50::kanMX4; sak1::HIS3 & This study \\
\hline rad50 $\Delta p s o 2 \Delta$ sak1 $\Delta$ & BY4742; with rad50::kanMX4; pso2::LEU2; sak1::HIS3 & This study \\
\hline $\operatorname{rad} 524$ & BY4742; with rad52::kanMX4 & Euroscarf \\
\hline $\operatorname{rad} 52 \Delta$ pso2A & BY4742; with rad52::kanMX4; pso2::LEU2 & This study \\
\hline
\end{tabular}

${ }^{a}$ Massachusetts General Hospital, Boston, MA, USA.

Table 2

Primers used in this study.

\begin{tabular}{|c|c|c|}
\hline Name & Sequence & Product lenght \\
\hline \multirow[t]{2}{*}{ pso2 $\triangle:: L E U 2$} & 5' ATGTCAAGGAAATCTATAGTGCAAATAAGAAGATCT GAAGGGTCAGGTTGCTTTCTCAGG 3' & $1790 \mathrm{bp}$ \\
\hline & 5' TTATTTAGCCGCCCGCGTTTTCCTAACGTTTTCCCAAC ATTTTATGCTTCCGGCTCGTAT 3’ & \\
\hline \multirow[t]{2}{*}{$\operatorname{sak} 1 \Delta:: H I S 3$} & 5' ATGGATAGGAGTGATAAAAAAGTTAACGTCGAAGAG GTCAGACACGTATAGAATGATGCA 3’ & $1151 \mathrm{bp}$ \\
\hline & 5' TCATGGAAGTGCACTCCTTCACTTCTCTTCATTTAGTTC AAGGTATCGTTAGAACACGGC 3' & \\
\hline \multirow[t]{2}{*}{ dnl4A::URA3 } & 5' ATGATATCAGCACTAGATTCTATACCCGAGCCCCAAAACTAGCAAAAACAGGAAGGCAAA 3' & $1592 \mathrm{bp}$ \\
\hline & 5' TCAGTAGTTGACTACGGGGAAGTCTTCTTCAGGCACTTGAAAGTTCACCTGTCCCACCTG 3' & \\
\hline \multirow[t]{2}{*}{ PSO2 } & 5' GAGACTATCTCTCAGTACTT 3' & $347 \mathrm{bp}$ \\
\hline & 5' ATTTTGGCGTTGCTTCGAAA 3' & \\
\hline \multirow[t]{2}{*}{ SAK1 } & 5' AGC GAT AAG TCA GGC TCC AA 3' & $633 \mathrm{bp}$ \\
\hline & $5^{\prime}$ ATG CAG CGT CAA GTC ATC CAT A 3' & \\
\hline \multirow[t]{2}{*}{ DNL4 } & 5' GATGCAAAAAGACGGGTGAT 3' & 924 bp \\
\hline & 5' CGCTTGATAGCTGGGGTTAG 3' & \\
\hline
\end{tabular}

\subsection{Yeast two-hybrid protein-protein interaction}

Two-hybrid analysis was essentially as described by Gyuris et al. [44]. Two in-frame fusions of the PSO2 ORF with the LexA DNA binding domain plasmid (pEG202) were constructed for screening and interaction analysis in THS. The LexAPSO2-A fusion contains the portion from aa 47 to 661 whereas LexAPSO2-B is a truncated construction (aa 47 to 466), lacking the last 195 aa of the C-terminal part. Both were constructed using internal EcoRI restriction sites and displayed no intrinsic transcriptional activation when transformed into strains containing reporter constructs regulated by LexA DNA-binding sites.

Yeast strain EGY48 containing the sensitive lacZ reporter plasmid pSH18-34 and the bait plasmid LexAPSO2-A was transformed with a yeast genomic library cloned into the prey plasmid pJG4-5 [41]. Plasmids were isolated from yeast that survived selection for leucine prototrophy on galactose and showed lacZ expression on X-Gal-galactose plates. E. coli strain KC8 was used for the rescue of the plasmids as described by Gyuris et al. [44]. Plasmid DNA was sequenced with an Applied Biosystems sequencer A377 (Foster City, CA). All obtained sequences were submitted to a BLAST search at MIPS (Munich Information Center for Protein Sequences) [45]. The expression of the LexA fusion baits were analyzed by western blotting using a monoclonal antibody against LexA (Clontech Laboratories Inc.) and by complementation assays in pso2 $\Delta$ mutants. $\beta$-galactosidase activity of the pSH18-34 two-hybrid reporter plasmid was assayed and quantified according to Burke et al. [43] using exponential phase cultures (approx. $2 \times 10^{7}$ cells $/ \mathrm{ml}$ ). Three to four individual transformants were assayed in liquid SynCo without the appropriate nutrients.

\subsection{Yeast survival assays}

Yeast exponential phase cells were obtained by inoculation of an isolated single colony into liquid YPD. Cells were washed in $0.9 \% \mathrm{NaCl}$ and re-suspended in phosphate-buffered saline 
(PBS - pH 7.4) to a titer of $1 \times 10^{8}$ cells/ml. In order to evaluate sensitivity to different mutagens, cells were treated in PBS with either UVC at doses ranging from 50 to $150 \mathrm{~J} / \mathrm{m}^{2} ; 8$-methoxypsoralen (Sigma) plus UVA (8-MOP+UVA) using UVA doses ranging from 0.1 to $1 \mathrm{~kJ} / \mathrm{m}^{2}$ [4]; nitrogen mustard [Bis(2-chloroethyl)amine hydrochloride, HN2 - Sigma] at concentrations from 6.25 to $50 \mu \mathrm{M}$, or with cisplatin [cis-diammine-dichloro-platinum(II), CDDP - Sigma] at concentrations from 50 to $800 \mu \mathrm{M}$. For UVC and 8-MOP+UVA treatments, cells were diluted in 1:10 serial steps immediately after irradiation and plated in triplicate on solid YPD. For HN2 and CDDP treatments, cells were incubated for $120 \mathrm{~min}$ in a rotary shaker at $30^{\circ} \mathrm{C}$ in the dark. After treatment, cells were appropriately diluted and plated in triplicate on solid YPD. All plates were incubated at $30^{\circ} \mathrm{C}$ for 3 days to determine survival. Assays were repeated at least three times, and plating was carried out in triplicate for each treatment. Data were analyzed by one-way analysis of variance (ANOVA) followed by Tukey's test, with $p<0.05$ considered as statistically significant.

\subsection{Over-expression and purification of recombinant GST-PSo2p and GST-Sak1p proteins}

For expression and purification of Pso2 protein, a $2734 \mathrm{bp}$ SnaBI-SacI-fragment from pDR3141 [18] was firstly sub-cloned into the Smal and BamHI sites of pUC18. From the resulting plasmid an internal 2014 bp BglII-BamHI PSO2 ORF containing fragment was cloned into the BamHI site of the vector pGEX-KG (Amersham Biosciences). The GST-Sak1 recombinant protein was obtained from pPH601 expression plasmid (kindly provided by R. Sclafani), which was constructed as described in Hovland et al. [37] into the EcoRI site of the vector pGEX-4T-2 (Pharmacia). The GST-Pso2p and GST-Sak1p fusion proteins were expressed in E. coli strain BL21(DE3)pLysS (Novagen) using $0.3 \mathrm{mM}$ isopropyl $\beta$-D-1-thiogalactopyranoside (IPTG, Sigma) for $180 \mathrm{~min}$ and affinity-purified on glutathione-Sepharose 4B (Amersham Biosciences) (Suppl. Fig. S1). Pso2p was obtained by thrombin (Amersham Bioscences) cleavage of GST-Pso2p according to the manufacturer's instructions. The protein purification process was monitored by SDS-12\% polyacrylamide gel stained with Coomassie Brilliant Blue G 250 .

\subsection{In vitro phosphorylation assay}

Pso2p $(8 \mu \mathrm{g})$ was incubated with either GST-Sak1p $(2 \mu \mathrm{g})$ or GST $(3 \mu \mathrm{g})$ in a protein phosphorylation buffer containing $50 \mathrm{mM}$ Tris- $\mathrm{HCl} \mathrm{pH} 7.5,15 \mathrm{mM} \mathrm{MgCl}_{2}, 1 \mathrm{mM}$ DTT, $5 \mu \mathrm{M}$ unlabeled ATP and $2 \mu \mathrm{Ci}$ of ${ }^{32} \mathrm{P}$-ATP $(3000 \mathrm{Ci} / \mathrm{mmol}$; Amersham Bioscences), at room temperature for $30 \mathrm{~min}$. Alternatively, GST-Sak1p was incubated alone in order to identify its autophosphorylation activity. The reactions were stopped by adding $10 \mu \mathrm{L}$ of $2 \times$ SDS sample buffer (0.125 M Tris- $\mathrm{HCl} \mathrm{pH} 6.8,4 \%$ SDS, 20\% glycerol, $0.3 \mathrm{M} \beta$-mercaptoethanol, $0.05 \%$ bromophenol blue) and boiling for $10 \mathrm{~min}$ before loading onto a $10 \%$ SDS-polyacrylamide gel. After electrophoresis, the gel was stained with Coomassie Brilliant Blue G 250, dried, and subjected to autoradiography.

\subsection{Preparation of yeast cell extracts}

Exponentially growing cells (approx. $10^{7}$ cells $/ \mathrm{ml}$ ) of the yeast strains BY4742 (WT), pso2 and sak1 were obtained by reinoculation of a overnight culture into $200 \mathrm{ml}$ of YPD to a titer of $5 \times 10^{6}$ cells $/ \mathrm{ml}$, incubated at $30^{\circ} \mathrm{C}$ on a rotatory shaker for $210 \mathrm{~min}$. Afterwards, the cells ( $\sim 50 \%$ budding cells) were resuspended in PBS to a titer of $1 \times 10^{8}$ cells $/ \mathrm{ml}$ and treated with 8-MOP+UVA with the UVA dose of $0.8 \mathrm{~kJ} / \mathrm{m}^{2}$, to increase $P S O 2$ expression. Following a period of $40 \mathrm{~min}$ in the dark, cells were washed in PBS and resuspended in ice-cold lysis buffer [50 $\mathrm{mM}$ Tris- $\mathrm{HCl} \mathrm{pH}$ 8.0, $200 \mathrm{mM} \mathrm{NaCl}$, protease inhibitors EDTA-free tablets (Roche)]. The cells were then lysed by vortexing with glass beads (Sigma) with twenty $10 \mathrm{~s}$ pulses, keeping the cells on ice between mixing. Whole-cell extracts were centrifuged to collect the supernatant. Total proteins were quantified using the Qubit ${ }^{\circledR}$ Fluorometer (Invitrogen), according to the manufacturer's instructions.

\subsection{Co-immunoprecipitation assays}

For co-immunoprecipitation assays, to each sample a total of $10 \mu \mathrm{g}$ of goat anti-Sak1 polyclonal antibody (Santa Cruz Biotechnology) were incubated with $10 \mu \mathrm{g}$ of Dynabeads ${ }^{\circledR}$ Protein G (Invitrogen) during $30 \mathrm{~min}$, for antibody binding. The following steps were performed according to manufacturer's instructions. Next, $1.5 \mathrm{mg}$ of yeast cell extracts were incubated with the beads-antibody complex for $3 \mathrm{~h}$ at $4{ }^{\circ} \mathrm{C}$ under gentle mixing condition. Proper controls without antibody ligation or without Dynabeads ${ }^{\circledR}$ Protein $\mathrm{G}$ were adopted. The proteins were eluted in $2 \times$ SDS sample buffer, at $80{ }^{\circ} \mathrm{C}$ for $10 \mathrm{~min}$, and then loaded onto an SDS-12\% polyacrylamide gel.

\subsection{Immunoblot analysis}

Proteins were electro-transferred to nitrocellulose membranes (Amersham) with a $300 \mathrm{~mA}$ current for $60 \mathrm{~min}$. Nitrocellulose sheets were then blocked by incubation with blocking buffer (5\% BSA and $0.05 \%$ Tween 20 in PBS) for $2 \mathrm{~h}$ at room temperature. Afterwards, membranes were incubated with rabbit anti-Pso2 polyclonal antibody, diluted 1:100 in blocking buffer for $3 \mathrm{~h}$. The anti-Pso2 antibody was produced by standard protocol, raised against purified recombinant GST-Pso2p, and adsorbed with $S$. cerevisiae pso $2 \Delta$ extract before use, to reduce background. Whole cell extracts from transformed $E$. coli strain BL21(DE3)pLysS overexpressing proteins Pso2 or Sak1 were used to ensure the detection of target proteins by the polyclonal antibodies. GST-Pso2p had a m.w. of about $100 \mathrm{kDa}$, which is in agreement with the expected size, while GST-Sak1p presented approximately $105 \mathrm{kDa}$, as described by Hovland et al. (1997) (Suppl. Fig. S2a). Additionally, the immunodetection was also performed with rabbit pre-immune serum and anti-Pso2 antibody, with whole-cell extract from $S$. cerevisiae WT strain, then confirming the antibody specificity for Pso2p (Suppl. Fig. S2b). Peroxidase-conjugated goat anti-rabbit IgG antibody (Santa Cruz Biotechnology), diluted 1:3000, was used as secondary antibody. Immunoreactive protein bands were detected with Pierce ECL Western Blotting Substrate (Thermo Scientific).

\section{Results}

\subsection{Isolation by THS of potential molecular partners of Pso2}

A two-hybrid screen was used to identify proteins that may physically interact with Pso2p. The fully complementing LexAPSO2-A bait (Fig. 1A) was used in the screening and a population of $2 \times 10^{6}$ individual transformants was obtained after transformation with the prey library. Aliquots were pooled and plated on selective medium containing galactose for testing induced expression of the activation domain fusion library. Some 320 clones were identified that allowed growth on SynCo-Leu as a result of the activation of the LexAop::LEU2 reporter construct. These clones were colony-purified, molecularly characterized by restriction mapping, and re-tested after re-transformation for their ability to activate Gal-inducible transcription of two reporter constructs (LexAop::LEU2 and pSH18-34) [44]. We found 47 transformants 
containing putative interactors, able to activate transcription of the two independent reporter constructs in the presence of LexAPSO2A. Further sequencing of the library plasmids revealed 13 different fusion protein products with 4 of them containing no real ORF subfragments or incorrect orientation. The remaining 9 different fusion protein products (Table 3 ) were unable to induce transcription when co-expressed with unrelated LexA DNA-binding domain fusions - pRFHM1 [37], LexAPSO5 (yeast RAD16 allele) and LexAHDF1 (yeast Ku70 protein) - indicating their LexAPSO2-A-specific interaction. Two of these putative Pso2p interacting proteins are encoded by ORFs with as yet unknown function. The remaining 7 are encoded by the genes NRK1, SAK1, APL6, FIR1, IFH1, REH1 and $A L Y 2$; their encoded proteins can roughly be grouped into six functional classes: (i) cell cycle and cell wall maintenance (NRK1); (ii) DNA synthesis (SAK1); (iii) RNA metabolism (FIR1 and IFH1); (iv) an APL3-complex associated protein (APL6), (v) protein synthesis - ribosomal large subunit biogenesis (REH1) and (vi) endocytosis of plasma membrane proteins ( $A L Y 2)$.

We focused our efforts on the study of Pso2p interaction with the most relevant candidate based on published data, i.e., on gene SAK1 that encodes protein kinase Sak1, which is capable of suppressing Pol $\alpha$ mutations via modification/stabilization of thermo-labile DNA polymerases during DNA repair [37] and also is an activating kinase of Snf1p under stress conditions [38]. The same C-terminal third of SAK1 ORF was independently isolated 6 times via THS. The domain isolated in the fusion protein encoded by $S A K 1$ is preceded by the kinase consensus motifs (aa 131-450) [37] and corresponds to the last C-terminal third of the protein (aa 618-1142). Using this part of the SAK1 coding region as query, the non-redundant database (NRDB) and domain databases at NCBI were searched using PSI-BLAST and RPS-BLAST, respectively, and no significant similarity to known deposited domains/proteins were highlighted within this region.

\subsection{Sak1p interacts with the conserved C-terminal -CASP domain of Pso2p}

To evaluate which part of Pso2p is required for interaction with its putative binding partner Sak1p, we firstly tested the ability of the Sak1p prey-fusion protein to induce the expression of lacZ and $L E U$ reporters in presence of the full PSO2 complementing bait LexAPSO2-A and the truncated construction LexAPSO2-B lacking the
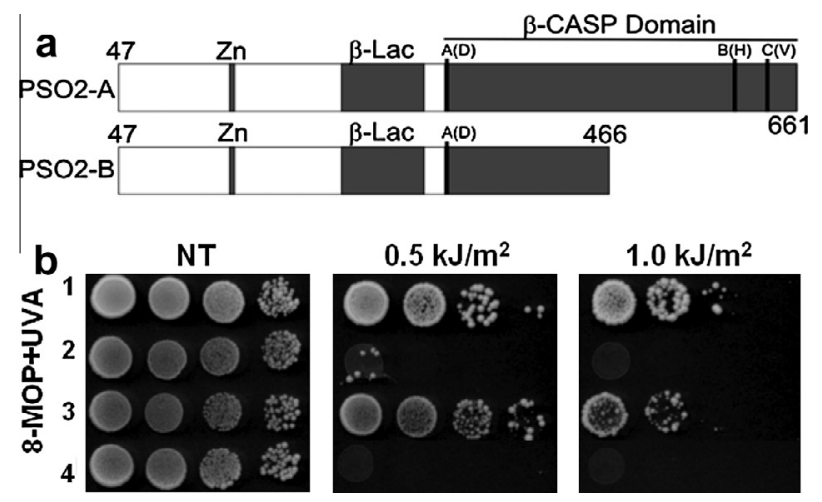

Fig. 1. LexAPSO2 bait constructs and complementation assays after mutagen treatment. (a) Length in aa of the LexAPSO2-A (PSO2-A) and LexAPSO2-B (PSO2-B) bait constructs and the position of predicted conserved domains: putative zinc finger domain $(\mathrm{Zn})$; $\beta$-lactamase $(\beta$-lac); and the $\beta$-CASP region with the three conserved motifs represented for $\beta$-CASP proteins acting on DNA substrates [A (aspartic acid), B (histidine) and C (valine)]. (b) 8-MOP+UVA treatment: (1) BY4742 (WT) strain containing the pEG202 empty plasmid, (2) pso2s strain containing the pEG202 empty plasmid, (3) pso2 $\Delta$ strain containing the LexAPSO2-A bait construction, (4) pso $2 \Delta$ strain containing the LexAPSO2-B bait construction.
C-terminal 195 aa. Deletion of the last 195 aa within the $\beta$-CASP domain in LexAPSO2-B failed to complement pso2s mutants (Fig. 1B) and, therefore, was used to determine if the conserved $\beta$-CASP domain, essential for WT-like DNA repair, also mediates interaction between its potential molecular partners. The SAK1 prey fusion product was able to activate both reporters (lacZ and $L E U$ ) in the presence of LexAPSO2-A bait (Leu prototrophy and blue color in galactose-containing SynCo) whereas interaction with LexAPSO2-B was considerably reduced (Table 4). This implies that the deletion of the last 195 aa within the conserved $\beta$-CASP domain specifically affects the interaction between Pso2p with the prey fusion encoded by SAK1.

\subsection{Genetic interaction between PSO2 and SAK1 after induced DNA damage}

Three putative PSO2 interactors SAK1, ALY2 and YHR080c were characterized for their response to mutagen treatment. The haploid mutants aly $2 \Delta$ and $y$ hr080c $\Delta$ showed WT-like sensitivity to 8-MOP+UVA, UVC, methyl methanesulfonate (MMS), Trenimon, and HN2 (data not shown), whereas the sak1 $\Delta$ strain was sensitive to 8-MOP+UVA, HN2 and CDDP (Fig. 2). Since all known pso2 mutant alleles confer high sensitivity to the ICL-inducing 8-MOP+UVA and HN2 treatments but are only moderately sensitive to UVC $[4,46]$, survival was determined in single and double mutants after treatments with these agents. Fig. 2A shows that the sak1 mutant allele does not affect the sensitivity to UVC compared to WT strain, while it confers sensitivity to 8-MOP+UVA and HN2 treatments (Fig. 2B and C). Furthermore, the double mutant pso2 $\Delta$ sak $1 \Delta$ yields cells with a pso2 $\Delta$-like sensitivity phenotype, implying an epistatic interaction of the two mutant alleles. Additionally, sak1 $\Delta$ strain showed sensitivity to CDDP (Fig. 2D), even though in a lesser extent, while pso2 $\Delta$ and pso2 $\Delta$ sak $1 \Delta$ mutants exhibited sensitivity comparable to that attained with 8-MOP+UVA and HN2 treatments. This survival data indicates that SAK1 gene is necessary for WT-resistance to 8-MOP+UVA, HN2 and CDDP, and the epistatic interaction of $s a k 1 \Delta$ with pso2 $\Delta$ points to its contribution in the same pathway specific for repair of DNA lesions induced by bi- or polyfunctional DNA damaging agents.

\subsection{Pso2p is phosphorylated by Sak1p in vitro}

Since Sak1p was found to interact with Pso2p in the THS screening we aimed to confirm this interaction with an in vitro protein interaction assay. As a kinase activity was described for Sak1p $[37,38]$ we asked whether Pso2p could be phosphorylated by Sak1p. Phosphorylation assay was carried out with heterologous expressed Pso2p and Sak1p. Results obtained in an in vitro phosphorylation assay are shown in Fig. 3. Also Sak1p autophosphorylation activity, firstly reported by Hovland et al. [37], was confirmed (105 kDa GST-Sak1p autophosphorylation signal; Fig. 3, lanes 1 and 2). When purified Pso2p was added, an additional phosphorylated protein signal was observed at the predicted size of Pso2p (76 kDa) (Fig. 3, lane 3). When the concentration of the purified Pso2 protein was increased in relation to that of Sak1p (Fig. 3, lanes 4, 6 and 7) an inhibition of the Sak1p phosphorylation activity was observed, suggesting a possible substrate inhibition effect or an allosteric mechanism. When Pso2p was incubated with GST (encoded by pGEX-KG empty plasmid) no detectable Pso2p phosphorylation occurred, thus showing that Sak1p is necessary for Pso2p phosphorylation in vitro (Fig. 3, lane 5). Some interfering signals of lower molecular weight than the expected for the proteins can be seen in the phosphorylation assay, which can be attributed to some protein degradation that occurred during the purification process. 
Table 3

Genes isolated in a two-hybrid screen using LexAPSO2-A as bait.

\begin{tabular}{|c|c|c|}
\hline Gene $^{a}$ & Gene/protein information ${ }^{\mathrm{b}, \mathrm{c}}$ & Extent of fusion ${ }^{\mathrm{d}}$ \\
\hline KIC1 (22) & $\begin{array}{l}\text { Ser/Thr protein kinase that interacts with Cdc31; required for cell integrity and morphogenesis; involved in cell wall biogenesis; } \\
3.8 \text { fold induction after MMS treatment; cytoplasmic localization; } \mathrm{CH} 139, \mathrm{CH} 361 \text {; } \mathrm{CH} 539\end{array}$ & Amino acids $832-1432$ \\
\hline SAK1 (6) & $\begin{array}{l}\text { DNA synthesis; protein kinase capable of suppressing DNA polymerase alpha mutations (cdc17-1); RAD9 gene product is required } \\
\text { for the suppression; upstream serine/threonine kinase for the SNF1 complex; partially redundant with Elm1 and Tos3; members } \\
\text { of this family have functional orthology with LKB1, a mammalian kinase associated with Peutz-Jeghers cancer-susceptibility } \\
\text { syndrome; CG166 }\end{array}$ & $\begin{array}{l}\text { C-terminal third of the } \\
\text { protein }\end{array}$ \\
\hline REH1 (4) & $\begin{array}{l}\text { Cytoplasmic } 60 \mathrm{~S} \text { subunit biogenesis factor, associates with pre-60S particles; similar to Rei1 and shares partially redundant } \\
\text { function in cytoplasmic } 60 \mathrm{~S} \text { subunit maturation; contains dispersed } \mathrm{C} 2 \mathrm{H} 2 \text { zinc finger domains }\end{array}$ & Amino acids $60-327$ \\
\hline $\begin{array}{l}\text { YKR015c } \\
(4)\end{array}$ & Putative protein of unknown function & $\begin{array}{l}\text { C-terminal third of the } \\
\text { protein }\end{array}$ \\
\hline APL6 (3) & $\begin{array}{l}\text { Beta3-like subunit of the yeast AP-3 complex; functions in transport of alkaline phosphatase to the vacuole via the alternate } \\
\text { pathway; exists in both cytosolic and peripherally associated membrane-bound pools }\end{array}$ & $\begin{array}{l}\text { C-terminal } 90 \text { amino } \\
\text { acids }\end{array}$ \\
\hline FIR1 (1) & 3' RNA processing/modification; interacts with REF2; a positive regulator of poly(A) synthesis & $\begin{array}{l}\text { Starts at amino acid } \\
251\end{array}$ \\
\hline IFH1 (1) & $\begin{array}{l}\text { Co-activator that regulates transcription of ribosomal protein (RP) genes; recruited to RP gene promoters during optimal growth } \\
\text { conditions via Fhl1; subunit of CURI, a complex that coordinates RP production and pre-rRNA processing }\end{array}$ & $\begin{array}{l}\text { C-terminal half of the } \\
\text { protein }\end{array}$ \\
\hline $\begin{array}{l}\text { YHR080c } \\
\text { (1) }\end{array}$ & $\begin{array}{l}\text { Protein of unknown function that may interact with ribosomes, based on co-purification experiments; the authentic, non-tagged } \\
\text { protein is detected in highly purified mitochondria in high-throughput studies; 6.2-fold induction after MMS treatment }\end{array}$ & Amino acids $340-713$ \\
\hline ALY2 (1) & $\begin{array}{l}\text { Alpha arrestin that controls nutrient-mediated intracellular sorting of permease Gap1; interacts with AP-1 subunit Apl4; } \\
\text { phosphorylated by Npr1 and also by cyclin-CDK complex Pcl7-Pho85; promotes endocytosis of plasma membrane proteins; } 1.7- \\
\text { fold induction after MMS treatment }\end{array}$ & $\begin{array}{l}\text { C-terminal half of the } \\
\text { protein }\end{array}$ \\
\hline
\end{tabular}

a Frequency of independent isolation is shown in parentheses.

b According to Güldener et al. [80] and SGD (http://genome-www.stanford.edu/Saccharomyces/).

c $\mathrm{CH \#}$ indicates association of the respective isolate with the protein complex reported by Ho et al. [81] and CG\# indicates association of the respective isolate with the protein complex reported by Gavin et al. [82].

d Segment of each ORF fused to the transcriptional activation domain constructs.

\subsection{PSO2 and SAK1 do not interact genetically with YKU70 after 8- MOP photoaddition}

DNA-ICL lesions are converted into DSBs during their processing [32], and the yeast Ku heterodimer (hereafter referred to as Ku; encoded by the YKU70 and YKU80 genes in S. cerevisiae) rapidly binds to DNA ends after DSB formation [47]. DSBs can be produced from cruciform structures that are formed in eukaryotic genome during replication and transcription [48-50] and in promoter regions of genes with inverted repeats [51], and in this case may result in hairpin-ended DSBs [52]. Thus we asked whether Pso2p endonuclease activity could be acting on these structures in the same pathway with YKu70p. Therefore, we tested YKU70, PSO2 and SAK1 mutant alleles, in single, double and triple combination mutants for their 8-MOP+UVA sensitivity.

We observed low to non-significant sensitivity to 8-MOP+UVA for the single mutant $y k u 70 \Delta$ (Fig. 4A), while significant and similar sensitivities were observed for single sak1 $\Delta$ and double $y k u 70 \Delta s a k 1 \Delta$ mutants (Fig. 4B). Mutants containing pso2 $\Delta s a k 1 \Delta$, $y k u 70 \Delta$ pso $2 \Delta$ as well as the $y k u 70 \Delta p s o 2 \Delta s a k 1 \Delta$ triple combination of mutant alleles all had a pso2 $\Delta$-like sensitivity phenotype (Fig. 4A). We also tested single- and double-disruptants for PSO2 and YKU70 genes for their HN2 sensitivity (Fig. 4C). Again, yku70 exhibited a WT-like HN2-sensitivity and did not influence the pso2 $\Delta$ sensitivity phenotype, indicating that gene YKU70 is involved in a step that is independent from PSO2 and SAK1 in the repair pathway of ICL damage in S. cerevisiae.

3.6. PSO2 and SAK1 exhibit a non-epistatic interaction with MRE11 and an epistatic interaction with RAD50 and XRS2 genes after ICL-induction

DSB formation can generate DNA clean (or free) ends accessible to downstream processing proteins, or modified ends (also called complex or dirty), which need further processing [53]. Similarly, hairpin-capped ends formed at DNA palindromes are inaccessible to nucleases [54,55]. Both modified and hairpin-capped ends depend on Mre11p/Rad50p/Xrs2p (MRX complex)-Sae2 factors to be made available for end resection, a necessary step for DNA repair [56]. Mre11 and Rad50 proteins encode a nuclease and a structural maintenance of chromosome-like protein, respectively. Xrs2 protein is involved in double strand breaks, meiotic recombination, telomere maintenance, and checkpoint signaling [56,57]. In order to examine a possible interaction of Pso2p and Sak1p with the MRX complex, we tested mutant alleles of MRE11, RAD50 and XRS2 genes in single, double and triple mutants with PSO2 and SAK1 genes to 8-MOP+UVA sensitivity. 8-MOP+UVA induced photolesions lead to the production of DSBs with complex DNA-ends $[58,59]$. The pso2 $\Delta$ and mre $11 \Delta$ single- and the mre $11 \Delta$ pso $2 \Delta$ double mutants were also tested for HN2 sensitivity.

Survival curves indicated a non-epistatic interaction between the genes MRE11 and PSO2.(Fig. 5A) and between MRE11 and SAK1 (Fig. 5B) after 8-MOP+UVA photoaddition. Meanwhile, the triple combination mutant mre $11 \Delta p s o 2 \Delta s a k 1 \Delta$ had a higher sensitivity when compared to all single and double mutants (Fig. 5A and B). This observed non-epistatic interaction for pso2 $\Delta$, mre $11 \Delta$, and mre $11 \Delta$ pso $2 \Delta$ in relation to the mre $11 \Delta$ pso2 $\Delta s a k 1 \Delta$ strain indicates that this mutant alleles are acting on the same substrate (and even competing for it), but not in the same repair pathway. The non-epistatic interaction for MRE11 and PSO2 genes observed after 8-MOP photoaddition (Fig. 5A) is also observed for HN2 treatment, in a more pronounced manner (Fig. 5C).

On the other hand, survival curves for rad50 mutants indicated similar sensitivity to the single mutants $\operatorname{rad} 50 \Delta$ and $p s o 2 \Delta$, the double mutants rad50 $\Delta$ pso $2 \Delta$ and rad50 $\Delta$ sak $1 \Delta$ and triple mutant rad50 $\Delta$ pso2 $\Delta s a k 1 \Delta$ (Fig. 5D and $\mathrm{E}$ ) after exposition to 8-MOP+UVA, indicating an epistatic interaction between these genes. This result suggests that Pso2p, Sak1p and Rad50p are acting in the same repair pathway for the repair of DNA-ICL lesions.

Survival curves for XRS2 gene mutants revealed that the double mutants $x r s 2 \Delta$ pso $2 \Delta$ and the triple mutant $x r s 2 \Delta$ pso $2 \Delta s a k 1 \Delta$ present a similar sensitivity to the single mutant $\operatorname{xrs} 2 \Delta$ after 8 -MOP photoaddition (Fig. 5F and G), thus presenting a lower sensitivity in relation to the single mutant $p s o 2 \Delta$. This indicates an epistatic interaction between PSO2 and XRS2 genes, and it is likely that the absence of $\mathrm{Xrs} 2 \mathrm{p}$ is recovering part of the sensitivity for pso2 $\Delta$ 
Table 4

Comparison of $\beta$-Galactosidase activity between Pso2p and Sak1 $\mathrm{p}^{\mathrm{a}}$ with either LexAPSO2-A or the LexAPSO2-B baits.

\begin{tabular}{|c|c|c|c|}
\hline \multirow[t]{2}{*}{ DNA binding domain plasmid (pEG202) } & \multirow[t]{2}{*}{ Activation domain plasmid (pJG4-5) } & \multicolumn{2}{|c|}{ Galactose } \\
\hline & & $\overline{\text { Leu }}$ & $\beta-$ Galactosidase activity \\
\hline pLexA GAL4 & pJG4-5 (HA-tagged) & ++ & $697 \pm 54.4$ \\
\hline pLexA Bicoid & pJG4-5 (HA-tagged) & - & $6.5 \pm 2.0$ \\
\hline LexAPSO2-A & pJG4-5-SAK1 (aa 618-1142) & ++ & $82.82 \pm 17.6$ \\
\hline LexAPSO2- $B$ & pJG4-5-SAK1 (aa 618-1142) & - & $3.5 \pm 2.3$ \\
\hline
\end{tabular}

a Plasmids that directed the synthesis of the DNA-binding domain (pEG202) and activation domain (pJG4-5) fusion proteins were introduced into EGY48. In addition to the

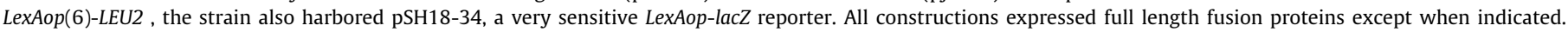

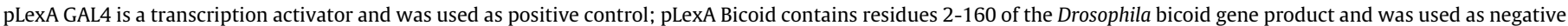
control.

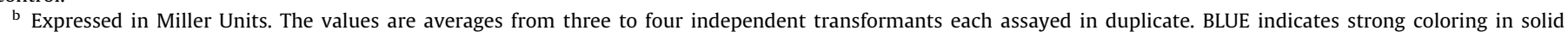
galactose SynCo media.
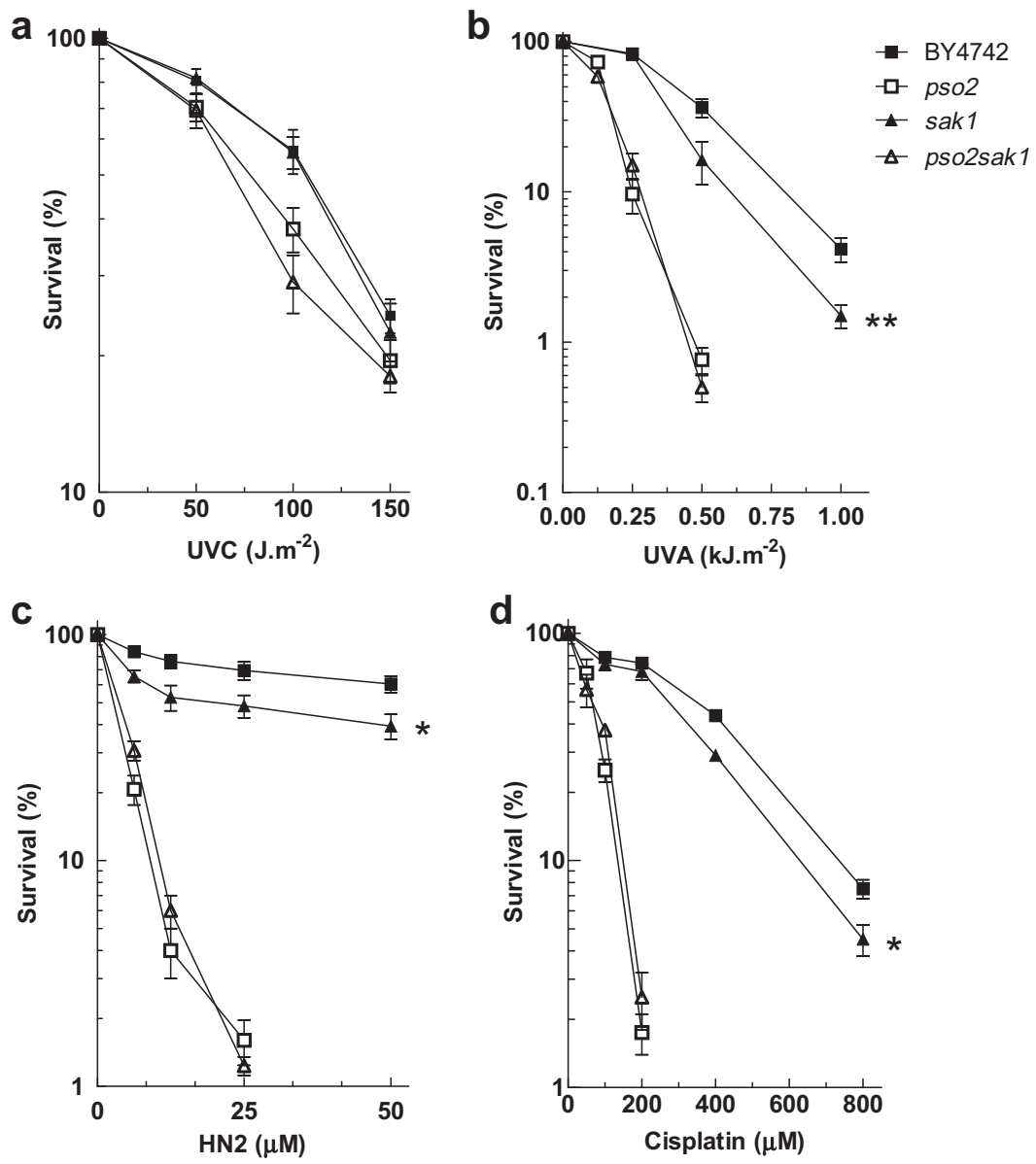

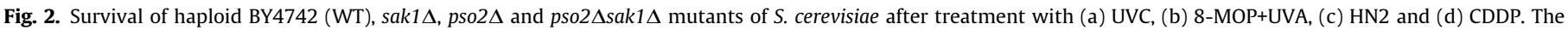
symbol $*$ represents $P<0.05$ and $* *$ represents $P<0.01$ as tested by one-way ANOVA (Tukey test): sak1 $\Delta$ mutants were compared to BY4742 (WT).

mutation alone. Interestingly, the double mutation $x r s 2 \Delta s a k 1 \Delta$ renders a phenotype more sensitive to 8-MOP+UVA treatment than the mutation sak1 $\Delta$ alone (Fig. 5G), indicating a non-epistatic interaction.

\subsection{PSO2 gene showed non-epistatic interaction with DNL4 after ICL induction in exponentially growing cells}

In addition to $\mathrm{Ku}$ and MRX complex, the core components of NHEJ machinery in S. cerevisiae also comprise Dnl4-Lif1 proteins, which are recruited rapidly to DSBs. DNL4 encodes a DNA ligase required for NHEJ at sites of DSBs. The interaction between Dnl4p with Lif1p is required in vivo for the stability of Ku binding to DSBs
[60]. Dnl4p may also play a role in an alternate microhomologymediated end-joining pathway (MMEJ) [57]. Since we observed that YKU70 does not interact genetically with PSO2 and SAK1 genes after ICL induction, we tested the sensitivity of mutants for Dnl4p against 8-MOP+UVA and HN2, to investigate the involvement of this member of NHEJ and MMEJ in ICL repair of exponentially growing yeast.

The survival curves indicated sensitivity similar to the WT of the single mutant $d n l 4 \Delta$ to 8 -MOP+UVA (Fig. $6 \mathrm{~A}$ ) and to HN2 (Fig. 6B) in presence of Pso2p, while similar low sensitivities were observed for single sak1 $\Delta$ and double $d n l 4 \Delta s a k 1 \Delta$ mutants. Otherwise, double mutant $d n l 4 \Delta$ pso $2 \Delta$ exhibited a more sensitive phenotype in relation to the single mutant pso2 $\Delta$ for both 8 -MOP 


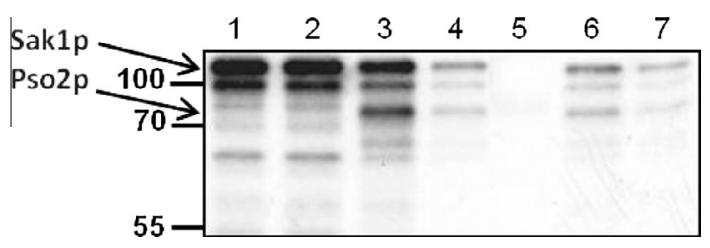

Fig. 3. In vitro phosphorylation of Pso2p by Sak1p. The arrows indicate position of the autophosphorylated Sak1 protein and the phosphorylated Pso2 protein. Molecular weight markers are indicated in kDa. Lanes (1) Sak1p; (2) Sak1p+trombin; (3) $8 \mu \mathrm{g}$ Pso2p+2 $\mu \mathrm{g}$ Sak1p; (4) $16 \mu \mathrm{g}$ Pso2p+2 $\mu \mathrm{g}$ Sak1p; (5) $8 \mu \mathrm{g}$ Pso2p+3 $\mu \mathrm{g}$ GST (control); (6) $24 \mu \mathrm{g}$ Pso2p+4 $\mu$ g Sak1p; (7) $40 \mu \mathrm{g}$ Pso2p+4 $\mu$ g Sak1p.

and HN2 treatments (Fig. 6A and B). These results indicate that Dnl4p is required for ICL repair in the absence of Pso2p.

\subsection{RAD52 and PSO2 genes interact epistatically after 8-MOP+UVA treatment in exponentially growing cells}

The initial stages of ICL repair, following the incisions of ICL by NER endonucleases, include repair by HR $[27,28,61]$. If DSBs ends are not rejoined by NHEJ, their $5^{\prime}$-to- $3^{\prime}$ nucleolytic degradation generates $3^{\prime}$-ended single-stranded DNA (ssDNA) tails that are essential for downstream HR events. Of all the members of the $R A D 52$ epistasis group, the absence of RAD52 confers the most severe defects because it is involved in multiple pathways of repairing DSBs. Rad52p assists in the displacement of RPA from ssDNA and stimulates Rad51-mediated strand exchange [62]. Rad52p plays a role in the synthesis-dependent strand annealing (SDSA), in break-induced replication (BIR) and in single-strand annealing (SSA) [63]. Henriques and Moustacchi [27] have reported that S. cerevisiae RAD52 and PSO2 genes have non-epistatic genetic interaction after 8-MOP photoaddition in stationary phase of $S$. cerevisiae. Since a homolog substrate is absent in stationary phase of cell growth, we investigate if the interaction of these repair genes in exponentially growing cells is the same after ICL induction. For this purpose, we tested the single and double mutants for PSO2 and RAD52 genes to 8-MOP+UVA sensitivity. We observed that pso2 $\Delta$ and rad52 $\Delta$ single mutants present the same high sensitivity as the rad52 $\Delta$ pso2 $\Delta$ double mutant (Fig. 7), indicating an epistatic interaction between these genes in ICL repair. Our results indicate that Pso2p and Rad52p act in the same pathway for ICL repair in exponentially growing cells.

\subsection{Sak1p binds to Pso2p after DNA ICL-induced damage}

In order to further confirm the physical interaction between Pso2p and Sak1p, we examined the association of these proteins by co-immunoprecipitation assays after ICL induction by 8-MOP+UVA. For the immunoprecipitation assays, whole-cell extracts were incubated with Dynabeads ${ }^{\circledR}$ Protein G linked to anti-Sak1 antibody; bound proteins were eluted, resolved by SDS-PAGE, and analyzed by immunoblotting with anti-Pso2 or anti-Sak1 antibody. As a pull-down control to the assays, no background could be attributed to Dynabeads-WT whole extract (Fig. 8, lane 2) and Dynabeads-Anti-Pso2 (Fig. 8, lane 3). Only the protein G ( $34 \mathrm{kDa})$ and the antibody heavy and light chains $(\sim 55 \mathrm{kDa}$ and $\sim 35 \mathrm{kDa}$, respectively) could be detected is these samples, as expected. The pull-down with anti-Sak1 antibody followed by incubation with anti-Pso2 originated a signal of Pso2p ( $\sim 76 \mathrm{kDa})$ for the WT strain (Fig. 8, lane 4) which was absent in pso2s mutant strain (Fig. 8, lane 5). Furthermore, a signal of approximately $130 \mathrm{kDa}$, corresponding to Sak1p [64] was observed for the WT sample, when
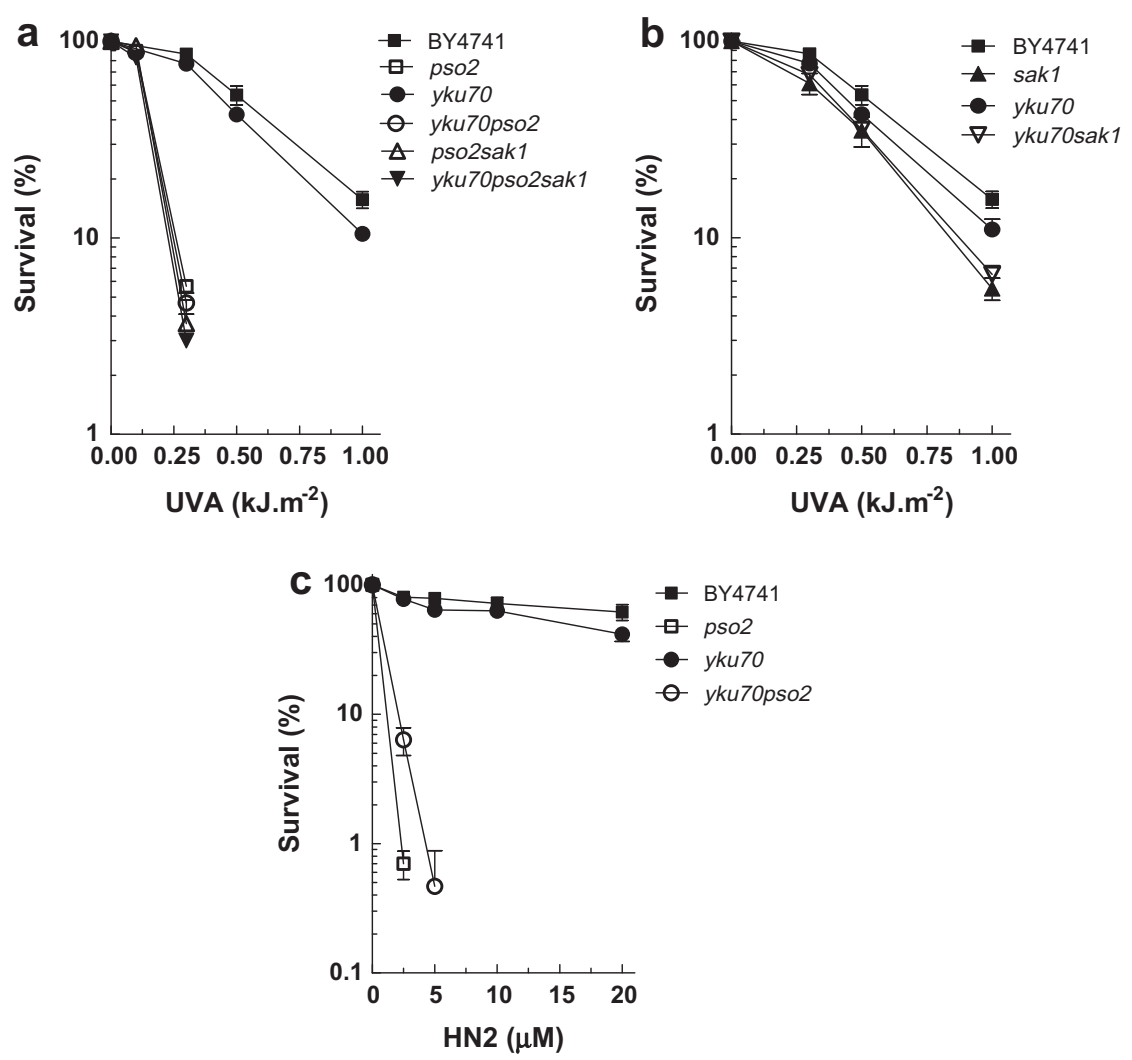

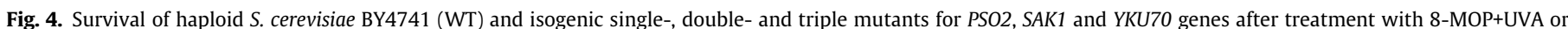

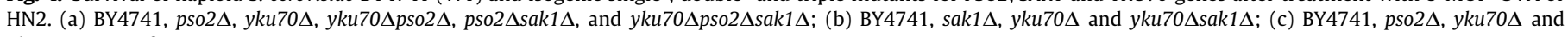
$y k u 70 \Delta$ pso $2 \Delta$ after HN2 treatment. 

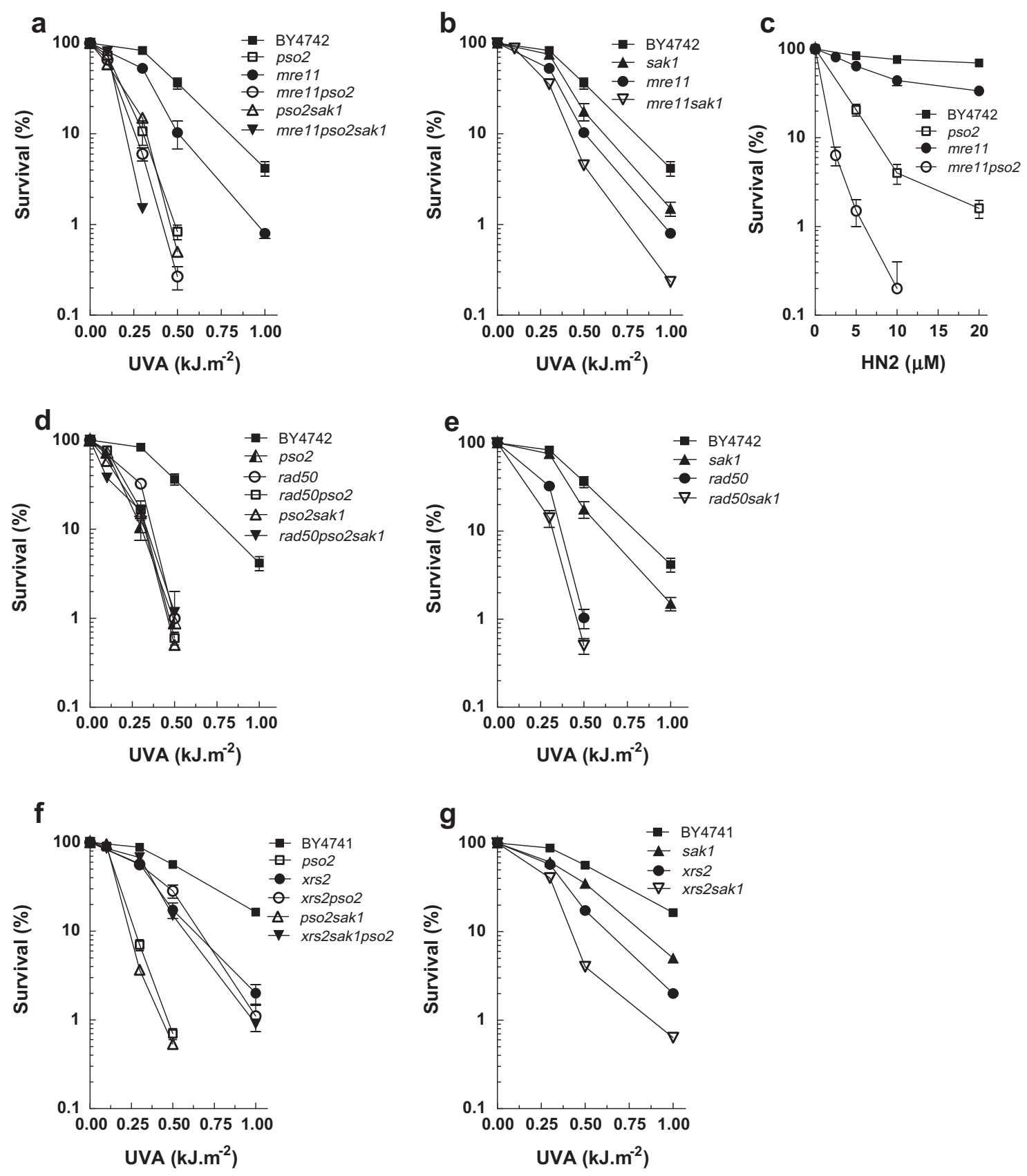

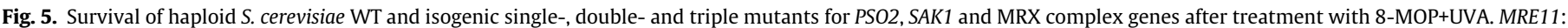

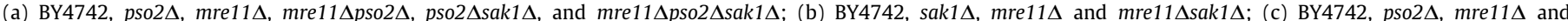

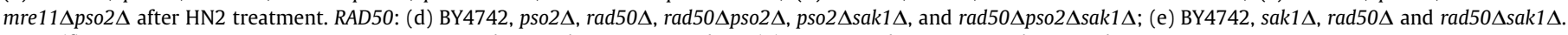

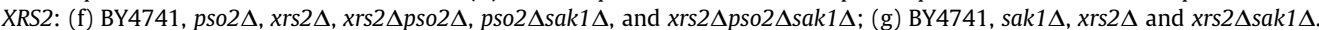

probed with anti-Sak1 antibody (Fig. 8, lane 6), which was absent

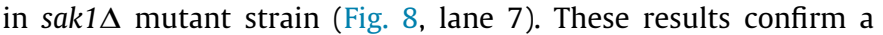
physical interaction between Pso2 nuclease and Sak1 kinase after ICL induction in exponentially growing $S$. cerevisiae.

\section{Discussion}

The pso2 and snm1 mutants were amongst the first yeast isolates found to be specifically sensitive to bi- or polyfunctional mutagens that produce the highly cytotoxic DNA-ICL lesions and, although being extensively studied, the role of $\mathrm{PSO} 2$ as well as of its orthologs in the removal of ICL from DNA is still not well understood [for review see 10,14,21,22]. In this work we isolated a set of putative interactors for Pso2p using the THS, besides confirming an epistatic interaction between Pso2p and Sak1p, therefore extending the characterization of PSO2 involvement in DNA-ICL repair.

Sak1p was the most interesting amongst the putative interactors found for Pso2p, and thus was further investigated. SAK1 encodes a Pol $\alpha$ suppressing protein kinase, which, when over-expressed, acts as a RAD9-dependent, allele-specific suppressor of thermo-labile Pol $\alpha$ mutations, a feature which suggested its possible involvement in cellular responses to DNA damage [37]. Sak1p also functions in S. cerevisiae as the primary Snf1 protein activating kinase [65] by phosphorylation in response to glucose limitation 

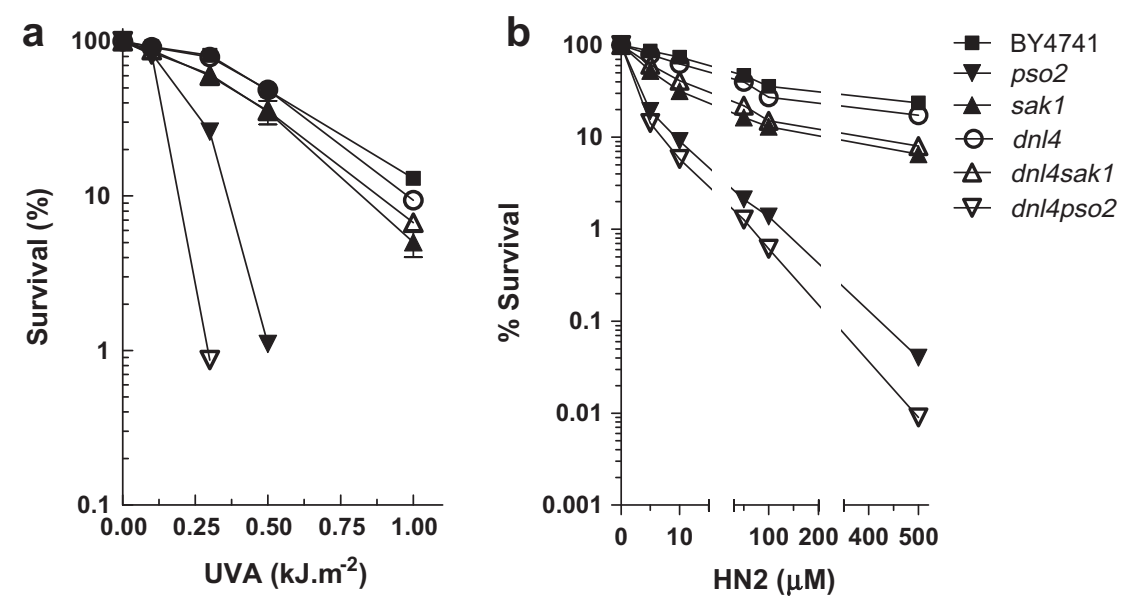

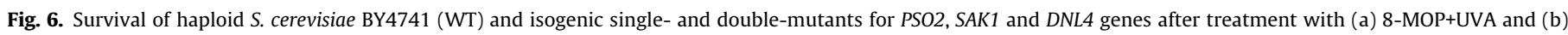
HN2.

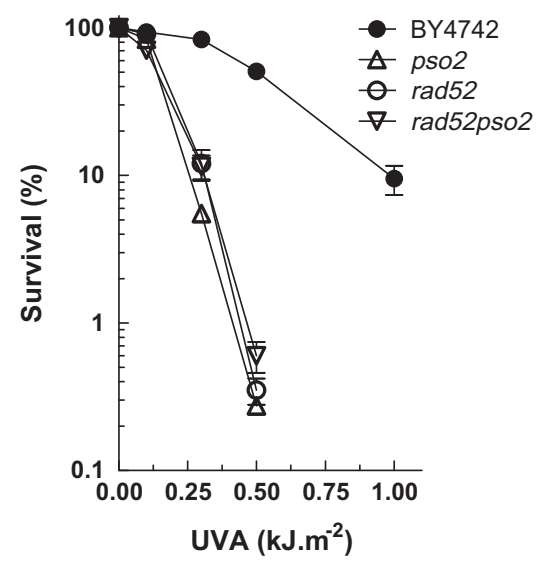

Fig. 7. Survival of haploid BY4742 (WT), pso2 $\Delta$, rad52 $\Delta$ and rad52 $\Delta$ pso2 $\Delta$ mutants of $S$. cerevisiae after treatment with 8-MOP+UVA, in exponential growth phase.

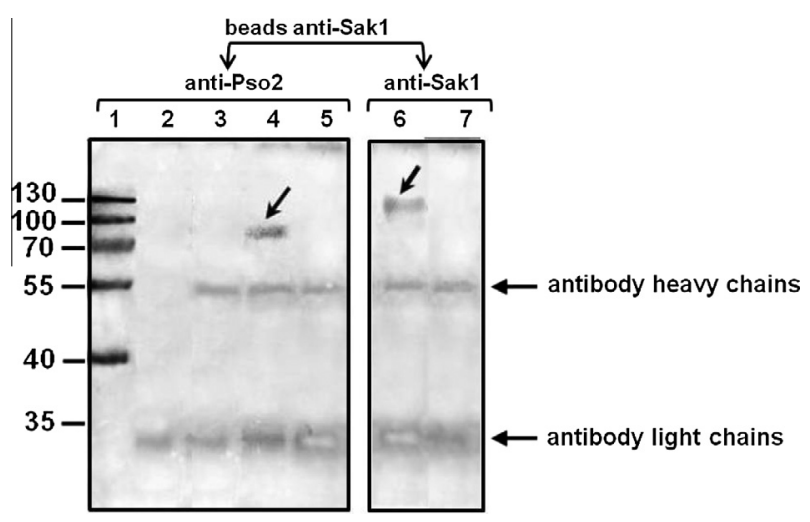

Fig. 8. Co-immunoprecipitation of Pso2p with Sak1p in S. cerevisiae, after 8MOP+UVA treatment. Proteins were immunoprecipitated from whole-cell extracts using anti-Sak1 polyclonal antibody. Bound proteins were gel-fractionated and analyzed on western blots probed with anti-Pso2 polyclonal antibody. Molecular weight markers are indicated (in kilodaltons). Lanes (1) PageRuler ${ }^{\mathrm{TM}}$ Prestained Protein Ladder (Fermentas); (2) WT strain BY472 with Dynabeads ${ }^{\circledR}$ Protein G; (3) Dynabeads ${ }^{\circledR}$ Protein G with anti-Sak1; $(4,6)$ WT strain BY4742; (5) pso2 $\Delta$ mutant; (7) sak1 $\Delta$ mutant. Immunoprecipitated Pso2p and Sak1p are indicated by arrows.

and other cellular stresses [38]. Snf1 (member of the SNF1/AMPactivated protein kinase family - AMPK), in turn, regulates the transcription of many genes involved in, e.g., meiosis and aging
[65]. Phosphorylation-based signaling is critical to almost all major cellular processes. Therefore, the isolation of a known protein kinase via THS was meaningful, demonstrating that Pso2p is a phosphorylation target of the Sak1p in vitro. The integrity of the conserved $\beta$-CASP domain of Pso2p was shown not only to be essential for WT-like DNA repair, confirming previous reports [9], but also to be necessary for interaction with Sak1p (Table 4).

As the sak1 $\Delta$ mutant had a DNA repair-deficiency phenotype, we first tested its genetic interaction with pso2 $\Delta$ mutant alleles in double mutant strains that contained ICL damage. According to survival analysis, $p s o 2 \Delta$ showed epistatic interaction with sak $1 \Delta$ for these treatments (Fig. 2). Indeed, a study using DNA microarray to examine genome-wide transcriptional changes in yeast in response to 8-MOP+UVA-induced ICL showed that SAK1 gene expression was strongly inducible by this treatment [59]. A sak1 $\Delta$ mutant displays less sensitivity to HN2 and CDDP than a pso2 $\Delta$ mutant. This may be caused by the lower stability characteristics of the DNA lesions induced by these agents [58] when compared to the extremely stable 8-MOP+UVA-induced ICL [66]. The DNA damage induced upon 8-MOP+UVA exposure differs strikingly from the UV radiation-induced pyrimidine dimers, the IR-induced singleand double-strand breaks and base lesions and the methylated bases induced by methyl methanesulfonate (MMS) [59]. Amongst the DNA lesions induced by 8-MOP+UVA, about 33\% comprise ICLs [66], while HN2 adducts consist of about 20\% ICLs [67] and CDDPinduced lesions comprise about 90\% intrastrand cross-links (Ia-CLs) and only 1-3\% ICLs [68]. Considering that ICLs are likely to be more difficult to repair than Ia-CLs, it is reasonable to expect different intermediate structures to be formed in the repair of CDDP-induced damage, which would not require Sak1p to the same extent. Our survival data thus indicate that Sak1p and Pso2p might function in the same pathway that controls sensitivity to DNA ICL-inducing agents.

We found that Pso2p is phosphorylated by Sak1 kinase in vitro (Fig. 3) and that these proteins physically interact after ICL induction (Fig. 8). This led us to ask what function this post-translational modification might have. It is known that phosphorylation of the C-terminal region of Artemis is required to relieve negative regulation of its endonuclease activity [25]. This fact highlights the importance for phosphorylation in regulating the nuclease function of Artemis. Previous results of a phylogram for Pso2p established by in silico studies clearly indicated a close phylogenetic relationship of Pso2p to the RAG-1/RAG-2 proteins that are known to have a function in $\mathrm{V}(\mathrm{D}) \mathrm{J}$ recombination [25], and thus can be biochemically defined as proteins with endonucleolytic 
and phosphotransferase activities $[10,14]$. This led to the hypothesis that Pso2p might have the ability to open fully paired hairpin structures $[10,25]$ a feature that was recently confirmed by Tiefenbach and Junop [12]. These authors not only proved endonucleolytic activity for Pso2p specific for the opening of closed DNA hairpin ends but also showed that both Pso2p exo- and endonucleolytic activities reside in the same active site. Based on these observations, we propose that phosphorylation of Pso2p by Sak1 kinase could modulate its exo-endonucleolytic activity, allowing the opening of hairpin structures formed due to DNA extrusion between a stalled replication fork and an ICL induced by bi- or polyfunctional DNA damaging-agents. However, the decrease in cell survival after treatment with 8 -MOP+UVA in sak1 $\Delta$ mutant is only modest. This implies that either Pso2p is active also in its nonphosphorylated form, or that there is another (or more) kinase(s) that can phosphorylate Pso2p in the absence of Sak1. The opening of DNA capped hairpin ends would render DNA ends able to be processed by downstream proteins of the repair pathway. Furthermore, incised ICL intermediates might also be resected by Pso2p 5 '-exonuclease activity (independent of phosphorylation) thus providing substrates for downstream reactions of DNA-ICL repair in yeast.

Our observation that YKU70 gene does not interact with PSO2 and SAK1 genes after cells have been exposed to ICL-inducing agents (Fig. 4) is in accordance with the findings of McHugh et al. [61] that investigated the survival and DSB repair in yeast cells following HN2 treatment, suggesting that NHEJ is not a major pathway for survival in either stationary or exponential phase, as well with findings of Dudás et al. [36], who reported no significant interaction within the pairwise combination Pso2+YKu70 in a comprehensive THS study. Our results indicate that Pso2p acts in ICL repair in a manner independent of YKu70p binding to DNA ends of a double strand break. In higher eukaryotes Ku promptly binds to DNA ends after DSB formation [47] and associates with the DNA-PKcs, which have kinase activity [69] and, in turn, phosphorylate SNM1C/Artemis [70]. Considering that no homolog for DNAPKcs has been identified in yeast [71] and that Pso2p presents both exo- and endonucleolytic activities, we suggest that Pso2 endonuclease may be acting on complex DSBs ends, which need further processing, thus preparing them for downstream processing proteins. This reaction may provide a substrate for a DSB repair pathway that differs from canonical NHEJ by dispensing Ku, i.e. MMEJ or SSA [63]. Absence of error-prone NHEJ would explain the fact that mutant pso2 $\Delta$ is blocked in mutagenesis $[10,72]$. Also, a recent work by Ward et al. [73] indicates that NHEJ plays a role in repair of HN2 induced ICL only in absence of functional Pso2p. The authors showed that a double mutant $d n l 4 \Delta p s o 2 \Delta$ presents enhanced sensitivity to HN2 in relation to the pso2 $\Delta$ single mutant, although the single mutant $d n l 4 \Delta$ demonstrated WT-like sensitivity. Our data for $d n l 4$ mutants after treatment with HN2 and 8-MOP+UVA (Fig. 6) are in accordance with those of Ward et al. [73], confirming the importance of Dnl4p for ICL repair in absence of Pso2p in yeast. DNL4 gene from $S$. cerevisiae encodes a DNA ligase required for NHEJ and also for MMEJ [57]. Nevertheless, Ma et al. [57] also observed that there was much less inhibition of DSB end repair in $d n l 4 \Delta$ mutants than was seen in $\operatorname{rad} 1 \Delta, y k u 70 \Delta$ or mre $11 \Delta$ cells. Thus, the moderate MMEJ impairment in the $d n l 4 \Delta$ mutant indicated that another ligase (very likely Cdc9) can also function in MMEJ. On the other hand, the epistatic interaction observed for PSO2 and RAD52 genes in exponentially growing cells after 8-MOP photoaddition (Fig. 7) indicates that Pso2p nuclease may provide a substrate for HR or SSA during ICL repair, since a homologous substrate is available. In stationary phase cells HR does not play a significant role in ICL repair, as previously demonstrated $[27,28]$. Alternative pathways for ICL repair and Pso2p involvement are discussed in a recent review of our group [74].
Our results for the non-epistatic interaction between $\mathrm{PSO} 2$ and MRE11 genes (Fig. 5A-C) are in agreement to previous data, which showed that Pso2p accounts for 95\% of the fully paired hairpin opening activity in S. cerevisiae [75]. Although both Pso2p and the MRX complex act on DNA hairpin processing, Pso2p is more efficient to open fully paired hairpins, while the MRX complex has a greater ability to process structures generated at long inverted repeats [56]. Moreover, resection of free DNA ends can occur in the absence of MRX and Sae2 nuclease, but resection of modified ends depends on these factors [53] and, as indicated by our study, it also depends on Pso2 nuclease and Sak1 kinase activities. These facts support the non-epistatic interaction observed between PSO2, SAK1 and MRE11 genes, where different pathways compete for the same substrate. Regarding the MRE11 gene, we observed that the pronounced increase in the sensitivity of the triple mutant mre $11 \Delta$ pso $2 \Delta$ sak $1 \Delta$ is due to deletion of SAK1 gene in conjunction with $P S O 2$ and MRE11, since the double mutants pso2 $\Delta \varpi$

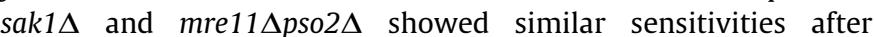
treatment with 8-MOP+UVA (Fig. 5A). This result corroborates the hypothesis that Sak1p is participating in more than one DNA repair pathways for ICL lesions, since the increased sensitivity observed for the triple mutant after treatment with photoactivated 8-MOP.

On the other hand, we observed an epistatic interaction for PSO2, SAK1 and RAD50 genes after 8-MOP photoaddition (Fig. 5D and E). Analyzing this result, in contrast with the non-epistatic interaction with MRE11 gene, it can be concluded that proteins Pso2p, Sak1p and Rad50p are acting in sequential steps in the same ICL repair pathway, whereas Mre11p acts in a parallel pathway. It is known that Rad50p may perform different functions at DSB ends [76]. In this case, Rad50p could be acting to maintain DSB ends close for processing by Pso2p and for required resection by exonucleases, exposing regions of homology.

Interestingly, disruption of XRS2 gene in a pso2 $\Delta$ background rendered a phenotype less sensitive to 8-MOP+UVA (Fig. 5F and $G)$. This result suggests that Pso2p and Xrs2p act in the same pathway of ICL repair in exponentially growing $S$. cerevisiae, and that $\mathrm{Xrs} 2 \mathrm{p}$ acts in a step prior to Pso2p. Possibly, in the absence of Xrs2p the substrate is diverted to an alternative pathway (without participation of Pso2p). The absence of functional Xrs2p prevents the recruitment of Rad50p and Mre11p to form the MRX complex [76]. However, the double mutant $x r s 2 \Delta s a k 1 \Delta$ is more sensitive in comparison to the corresponding single mutants, suggesting a non-epistatic interaction. As PSO2 do not contribute to the sensitivity in absence of XRS2, the enhanced sensitivity of $x r s 2 \Delta s a k 1 \Delta$ mutant could suggest that $S A K 1$ is also required for alternative Pso2p-independent pathway in absence of Xrs2p.

Even though the mechanistic details of ICL repair have yet to be clarified, Pso2p certainly plays a central role in ICL removal in yeast [22]. The PSO2/SNM1 gene family has a clear role in the maintenance of genomic integrity, and is present from bacteria to humans. In addition, Bonatto et al. [15] identified the $\beta$-CASP domain in plants, which was recently characterized in Arabidopsis thaliana [77], thus extending the distribution of Pso2/SNM1 protein family to plants. In this report, we have identified new features on Pso2p interaction with a protein kinase and interaction with members of the HR and non-homologous recombination pathways, thus allowing a better understanding of its activity on intermediate structures formed during repair of DNA ICLs. There are a number of reports that in yeast further processing of intermediate structures generated during ICL-repair involves proteins of NER as well as of HRR, NHEJ and TLS [12,27,34,61,78,79], indicating a high degree of redundancy and versatility in the response to this type of DNA damage. Further studies will be required to elucidate some aspects of Pso2 function to define how the various sub-pathways contribute to the post incision steps of ICL repair in yeast. 


\section{Acknowledgements}

We thank Dr. R. Brent for kindly providing plasmids and strains, Dr. Heidi Feldmann for the valuable contribution with the two-hybrid analysis, and Rodrigo M. Carlessi and Dr. Odir A. Dellagostin (Universidade Federal de Pelotas, Brazil) for antibody production. FMM held fellowship of CAPES. LFR held fellowship of CNPq. Collaborative research was sponsored by DAAD-CAPES, DAAD-CNPq travel grants to LFR, MB and JAPH. This work was supported by PRONEX/FAPERGS/CNPq 10/004-3 and Genotox-Royal Institute.

\section{Appendix A. Supplementary material}

Supplementary data associated with this article can be found, in the online version, at http://dx.doi.org/10.1016/j.jphotobiol.2013. 11.024 .

\section{References}

[1] M. Brendel, J.A.P. Henriques, The pso mutants of Saccharomyces cerevisiae comprise two groups: one deficient in DNA repair and another with altered mutagen metabolism, Mutat. Res. 489 (2001) 79-96.

[2] K.M. Vasquez, Targeting and processing of site-specific DNA interstrand crosslinks, Environ. Mol. Mutagen. 51 (2010) 527-539.

[3] Y.M.N. Akkari, R.L. Bateman, C.A. Reifsteck, S.B. Olson, M. Grompe, DNA replication is required to elicit cellular responses to psoralen-induced DNA interstrand cross-links, Mol. Cell. Biol. 20 (2000) 8283-8289.

[4] J.A.P. Henriques, E. Moustacchi, Isolation and characterization of pso mutants sensitive to photoaddition of psoralen derivatives in Saccharomyces cerevisiae, Genetics 95 (1980) 273-288.

[5] W. Siede, M. Brendel, Isolation and characterization of yeast mutants with thermoconditional sensitivity to the bifunctional alkylating agent nitrogen mustard, Curr. Genet. 4 (1981) 145-149.

[6] C. Cassier-Chauvat, E. Moustacchi, Allelism between pso1-1 and rev3-1 mutants and between pso2-1 and snm 1 mutants in Saccharomyces cerevisiae, Curr. Genet. 13 (1988) 37-40.

[7] J.A.P. Henriques, M. Brendel, The role of PSO and SNM genes in dark repair of the yeast Saccharomyces cerevisiae, Curr. Genet. 18 (1990) 387-393.

[8] J.A.P. Henriques, J. Brozmanova, M. Brendel, Role of PSO genes in the repair of photoinduced interstrand cross-links and photooxidative damage in the DNA of the yeast Saccharomyces cerevisiae, J. Photochem. Photobiol. B 39 (1997) 185-196.

[9] X. Li, R.E. Moses, The beta-lactamase motif in Snm1 is required for repair of DNA double-strand breaks caused by interstrand crosslinks in S. cerevisiae DNA Repair 2 (2003) 121-129.

[10] M. Brendel, D. Bonatto, M. Strauss, L.F. Revers, C. Pungartnik, J. Saffi, J.A.P. Henriques, Role of PSO genes in repair of DNA damage of Saccharomyces cerevisiae, Mutat. Res. 544 (2003) 179-193.

[11] X. Li, J. Hejna, R.E. Moses, The yeast Snm1 protein is a DNA 5'-exonuclease, DNA Repair 4 (2005) 163-170.

[12] T. Tiefenbach, M. Junop, Pso2 (SNM1) is a DNA structure-specific endonuclease, Nucl. Acids Res. 40 (2012) 2131-2139.

[13] I. Callebaut, D. Moshous, J.P. Mornon, J.P. de Villartay, Metallo-beta-lactamase fold within nucleic acids processing enzymes: the beta-CASP family, Nucl. Acids Res. 30 (2002) 3592-3601.

[14] D. Bonatto, L.F. Revers, M. Brendel, J.A.P. Henriques, The eukaryotic Pso2/ Snm1/Artemis proteins and their function as genomic and cellular caretakers, Braz. J. Med. Biol. Res. 38 (2005) 321-334.

[15] D. Bonatto, M. Brendel, J.A.P. Henriques, A new group of plant-specific ATPdependent DNA ligases identified by protein phylogeny, hydrophobic cluster analysis and 3-dimensional modeling, Funct. Plant. Biol. 32 (2005) 161-174.

[16] C. Lenain, S. Bauwens, S. Amiard, M. Brunori, M.J. Giraud-Panis, E. Gilson, The Apollo 52 exonuclease functions together with TRF2 to protect telomeres from DNA Repair, Curr. Biol. 16 (2006) 1303-1310.

[17] J. Hejna, S. Philip, J. Ott, C. Faulkner, R. Moses, The hSNM1 protein is a DNA 5'exonuclease, Nucl. Acids Res. 35 (2007) 6115-6123.

[18] D. Richter, E. Niegemann, M. Brendel, Molecular structure of the DNA crosslink repair gene SNM1 (PSO2) of the yeast Saccharomyces cerevisiae, Mol. Gen. Genet. 231 (1992) 194-200.

[19] R. Wolter, W. Siede, M. Brendel, Regulation of SNM1, an inducible Saccharomyces cerevisiae gene required for repair of DNA cross-links, Mol. Gen. Genet. 250 (1996) 162-168.

[20] X. Zhang, C. Richie, R.J. Legerski, Translation of hSNM1 is mediated by an internal ribosome entry site that upregulates expression during mitosis, DNA Repair 1 (2002) 379-390.

[21] Y. Yan, S. Akhter, X. Zhang, R. Legerski, The multifunctional SNM1 gene family: not just nucleases, Future Oncol. 6 (2010) 1015-1029.

[22] E. Cattell, B. Sengerová, P.J. McHugh, The SNM1/Pso2 family of ICL repair nucleases: from yeast to man, Environ. Mol. Mutagen. 51 (2010) 635-645.
[23] A. Hazrati, M. Ramis-Castelltort, S. Sarkar, L.J. Barber, C.J. Schofield, J.A. Hartley, P.J. McHugh, Human SNM1A suppresses the DNA repair defects of yeast pso2 mutants, DNA Repair 7 (2008) 230-238.

[24] D. Bonatto, M. Brendel, J.A.P. Henriques, The eukaryotic Pso2p/Snm1p family revisited: in silico analyses of Pso2p A, B and Plasmodium groups, Comput. Biol. Chem. 29 (2005) 420-433.

[25] Y. Ma, U. Pannicke, K. Schwarz, M.R. Lieber, Hairpin opening and overhang processing by an Artemis/DNA-dependent protein kinase complex in nonhomologous end joining and V(D)J recombination, Cell 108 (2002) 781794.

[26] D. Moshous, I. Callebaut, R. de Chasseval, B. Corneo, M. Cavazzana-Calvo, F. Le Deist, I. Tezcan, O. Sanal, Y. Bertrand, N. Philippe, A. Fischer, J.P. de Villartay, Artemis, a novel DNA double-strand break repair/V(D)J recombination protein, is mutated in human severe combined immune deficiency, Cell 105 (2001) 177-186.

[27] J.A.P. Henriques, E. Moustacchi, Interaction between mutations for sensitivity to psoralen photoaddition (pso) and to radiation (rad) in Saccharomyces cerevisiae, J. Bacteriol. 148 (1981) 248-256.

[28] W. Jachymczyk, R. von Borstel, M. Mowat, P. Hastings, Repair of interstrand cross-links in DNA of Saccharomyces cerevisiae requires two systems for DNA repair: the RAD3 system and the RAD51 system, Mol. Gen. Genet. 182 (1981) 196-205.

[29] S. Sarkar, A. Davies, H.D. Ulrich, P.J. McHugh, DNA interstrand crosslink repair during G1 involves nucleotide excision repair and DNA polymerase zeta, EMBO J. 25 (2006) 1285-1294.

[30] J.J. Rahn, G.M. Adair, R.S. Nairn, Multiple roles of ERCC1-XPF in mammalian interstrand crosslink repair, Environ. Mol. Mutagen. 51 (2010) 567-581.

[31] T.V. Ho, A. Guainazzi, S.B. Derkunt, M. Enoiu, O.D. Schärer, Structuredependent bypass of DNA interstrand crosslinks by translesion synthesis polymerases, Nucl. Acids Res. 39 (2011) 7455-7464.

[32] P. Lehoczký, P.J. McHugh, M. Chovanec, DNA interstrand cross-link repair in Saccharomyces cerevisiae, FEMS Microbiol. Rev. 31 (2007) 109-133.

[33] T.V. Ho, O.D. Schärer, Translesion DNA synthesis polymerase in DNA interstrand crosslink repair, Environ. Mol. Mutagen. 51 (2010) 552-566.

[34] N. Magaña-Schwencke, J.A.P. Henriques, R. Chanet, E. Moustacchi, The fate of 8-methoxypsoralen photoinduced crosslinks in nuclear and mitochondrial yeast DNA: comparison of wild-type and repair-deficient strains, Proc. Natl. Acad. Sci. USA 79 (1982) 1722-1726.

[35] F. Wilborn, M. Brendel, Formation and stability of interstrand cross-links induced by cis-diamminedichloroplatinum and transdiamminedichloroplatinum (II) in the DNA of Saccharomyces cerevisiae strains differing in repair capacity, Curr. Genet. 16 (1989) 331-338.

[36] A. Dudás, D. Vlasáková, Z. Dudásová, D. Gabcová, J. Brozmanová, M. Chovanec Further characterization of the role of Pso2 in the repair of DNA interstrand cross-link-associated double-strand breaks in Saccharomyces cerevisiae, Neoplasma 54 (2007) 189-194.

[37] P.G. Hovland, M. Tecklenberg, R.A. Sclafani, Overexpression of the protein kinase Pak1 suppresses yeast DNA polymerase mutations, Mol. Gen. Genet. 256 (1997) 45-53.

[38] S.P. Hong, F.C. Leiper, A. Woods, D. Carling, M. Carlson, Activation of yeast Snf1 and mammalian AMP-activated protein kinase by upstream kinases, Proc. Natl. Acad. Sci. USA 100 (2003) 8839-8843.

[39] R.J. Rothstein, One-step gene disruption in yeast, Methods Enzymol. 101 (1983) 202-211.

[40] F. Ausubel, R. Brent, R.E. Kingston, D.D. Moore, J.G. Seidman, J.A. Smith, K Struhl, Short Protocols in Molecular Biology, third ed., John Wiley \& Sons Inc, New York, 1995.

[41] P.M. Watt, E.J. Louis, R.H. Borts, I.D. Hickson, Sgs1: A eukaryotic homolog of E. coli RecQ that interacts with topoisomerase II in vivo and is required for faithful chromosome segregation, Cell 81 (1995) 253-260.

[42] J. Sambrook, D. Russell, Molecular Cloning: A Laboratory Manual, third ed. Cold Spring Harbour Laboratory Press, New York, 2001.

[43] D. Burke, D. Dawson, T. Stearns, Methods in Yeast Genetics - Cold Spring Harbour Laboratory Course Manual, Cold Spring Harbour Laboratory Press, New York, 2000.

[44] J. Gyuris, E. Golemis, H. Chettkov, R. Brent, Cdi1, a human G1 and S phase protein phosphatase that associates with Cdk2, Cell 75 (1993) 791-803.

[45] H.W. Mewes, D. Frishman, C. Gruber, B. Geier, D. Haase, A. Kaps, K. Lemcke, G. Mannhaupt, F. Pfeiffer, C. Schüller, S. Stocker, B. Weil, MIPS: a database for genomes and protein sequences, Nucl. Acids Res. 28 (2000) 37-40.

[46] A. Ruhland, E. Haase, W. Siede, M. Brendel, Isolation of yeast mutants sensitive to the bifunctional alkylating agent nitrogen mustard, Mol. Gen. Genet. 181 (1981) 346-351.

[47] W. Wu, M. Wang, S.K. Singh, T. Mussfeldt, G. Iliakis, Repair of radiation induced DNA double strand breaks by backup NHEJ is enhanced in G2, DNA Repair 7 (2008) 329-338.

[48] E. Palecek, Local supercoil-stabilized DNA structures, Crit. Rev. Biochem. Mol Biol. 26 (1991) 151-226.

[49] K. van Holde, J. Zlatanova, Unusual DNA structures, chromatin and transcription, Bioessays 16 (1994) 59-68.

[50] C.T. Lin, Y.L. Lyu, L.F. Liu, A cruciform-dumbbell model for inverted dimer formation mediated by inverted repeats, Nucl. Acids Res. 25 (1997) 30093016.

[51] V. Brázda, R.C. Laister, E.B. Jagelská, C. Arrowsmith, Cruciform structures are a common DNA feature important for regulating biological processes, BMC Mol. Biol. 12 (2011) 33. 
[52] S.M. Lewis, A.G. Coté, Palindromes and genomic stress fractures: bracing and repairing the damage, DNA Repair 5 (2006) 1146-1160.

[53] L.S. Symington, J. Gautier, Double-strand break end resection and repair pathway choice, Annu. Rev. Genet. 45 (2011) 247-271.

[54] L. Balakrishnan, P. Polaczek, S. Pokharel, J.L. Campbell, R.A. Bambara, Dna2 exhibits a unique strand end-dependent helicase function, J. Biol. Chem. 285 (2010) 38861-38868.

[55] B.I. Lee Bi, L.H. Nguyen, D. Barsky, M. Fernandes, D.M. Wilson, Molecular interactions of human Exo1 with DNA, Nucl. Acids Res. 30 (2002) 942-949.

[56] K.S. Lobachev, D.A. Gordenin, M.A. Resnick, The Mre11 complex is required for repair of hairpin-capped double-strand breaks and prevention of chromosome rearrangements, Cell 108 (2002) 183-193.

[57] J. Ma, E.M. Kim, J.E. Haber, S.E. Lee, Yeast Mre11 and Rad1 proteins define a Kuindependent mechanism to repair double-strand breaks lacking overlapping end sequences, Mol. Cell Biol. 23 (2003) 8820-8828.

[58] H. Zheng, X. Wang, R.J. Legerski, P.M. Glazer, L. Li, Repair of DNA interstrand cross-links: interactions between homology-dependent and homologyindependent pathways, DNA Repair 5 (2006) 566-574.

[59] M. Dardalhon, W. Lin, A Nicolas, D. Averbeck, Specific transcriptiona responses induced by 8-methoxypsoralen and UVA in yeast, FEMS Yeast Res. 7 (2007) 866-878.

[60] Y. Zhang, M.L. Hefferini, L. Chen, E.Y. Shim, H.M. Tseng, Y. Kwon, P. Sung, S.E. Lee, A.E. Tomkinson, Role of Dnl4-Lif1 in nonhomologous end-joining repair complex assembly and suppression of homologous recombination, Nat. Struct. Mol. Biol. 14 (2007) 639-646.

[61] P.J. McHugh, W.R. Sones, J.A. Hartley, Repair of intermediate structures produced at DNA interstrand cross-links in Saccharomyces cerevisiae, Mol Cell. Biol. 20 (2000) 3425-3433.

[62] J.M. Hinz, Role of homologous recombination in DNA interstrand crosslink repair, Environ. Mol. Mutagen. 51 (2010) 582-603.

[63] L.S. Symington, Role of RAD52 epistasis group genes in homologous recombination and double-dtrand break repair, Microbiol. Mol. Biol. Rev. 66 (2002) 630-670.

[64] K. Elbing, R.R. McCartney, M.C. Schmidt, Purification and characterization of the three Snf1-activating kinases of Saccharomyces cerevisiae, Biochem. J. 393 (2006) 797-805.

[65] Y. Liu, X. Xu, M. Carlson, Interaction of SNF1 protein kinase with its activating kinase Sak1, Eukaryotic Cell 10 (2011) 313-319.

[66] J.A.P. Henriques, H.H. Andrade, M. Bankmann, M. Brendel, Reassessing the genotoxic potential of 8-MOP+UVA-induced DNA damage in the yeast Saccharomyces cerevisiae, Curr. Genet. 16 (1989) 75-80.

[67] M. Kircher, M. Brendel, DNA alkylation by mustard gas in yeast strains of different repair capacity, Chem. Biol. Interact. 44 (1983) 27-39.

[68] M. Kartalou, L.D. Samson, J.M. Essigmann, Cisplatin adducts inhibit 1, N(6) ethenoadenine repair by interacting with the human 3-methyladenine DNA glycosylase, Biochemistry 39 (2000) 8032-8038.

[69] C.W. Anderson, S.P. Lees-Miller, The nuclear serine/threonine protein kinase DNA-PK, Crit. Rev. Eukaryotic Gene Expr. 2 (1992) 283-314.

[70] Y. Ma, U. Pannicke, H. Lu, D. Niewolik, K. Schwarz, M.R. Lieber, The DNAdependent protein kinase catalytic subunit phosphorylation sites in human Artemis, J. Biol. Chem. 280 (2005) 33839-33846.
[71] A. Jazayeri, S.P. Jackson, Screening the yeast genome for new DNA-repair genes, Genome Biol. 3 (2002) 1009.1-1009.5.

[72] C. Cassier, R. Chanet, J.A.P. Henriques, E. Moustacchi, The effects of three PSO genes on induced mutagenesis: a novel class of mutationally defective yeast, Genetics 96 (1980) 841-857.

[73] T.A. Ward, Z. Dudášová, S. Sarkar, M.R. Bhide, D. Vlasáková, M. Chovanec, P.J. McHugh, Components of a Fanconi-like pathway control Pso2-independent DNA interstrand crosslink repair in yeast, PLoS Genet. 8 (2012) e1002884.

[74] F.M. Munari, T.N. Guecheva, D. Bonatto, J.A.P. Henriques, New features on Pso2 protein family in DNA interstrand cross-link repair and in the maintenance of genomic integrity in Saccharomyces cerevisiae, Fungal Genet. Biol. 60 (2013) $122-132$.

[75] A.F. Lam, B.O. Krogh, L.S. Symington, Unique and overlapping functions of the Exo1, Mre11 and Pso2 nucleases in DNA repair, DNA Repair 7 (2008) 655-662.

[76] D. D'Amours, S.P. Jackson, The MRE11 complex: at the crossroads of DNA repair and checkpoint signalling, Nat. Rev. Mol. Cell Biol. 3 (2002) 317-327.

[77] W.M. Waterworth, G. Masnavi, R.M. Bhardwaj, Q. Jiang, C.M. Bray, C.E. West, A plant DNA ligase is an important determinant of seed longevity, Plant J. 63 (2010) 848-860.

[78] J. Yu, K. Marshall, M. Yamaguchi, J.E. Haber, C.F. Weil, Microhomologydependent end joining and repair of transposon-induced DNA hairpins by host factors in Saccharomyces cerevisiae, Mol. Cell. Biol. 24 (2004) 1351-1364.

[79] L.J. Barber, T.A. Ward, J.A. Hartley, P.J. McHugh, DNA interstrand cross-link repair in the Saccharomyces cerevisiae cell cycle: overlapping roles for PSO2 (SNM1) with MutS factors and EXO1 during S Phase, Mol. Cell. Biol. 25 (2005) 2297-2309.

[80] U. Güldener, M. Münsterkötter, G. Kastenmüller, N. Strack, J. van Helden, C. Lemer, J. Richelles, S.J. Wodak, J. García-Martínez, J.E. Pérez-Ortín, H. Michael, A. Kaps, E. Talla, B. Dujon, B. André, J.L. Souciet, J. de Montigny, E. Bon, C. Gaillardin, H.W. Mewes, CYGD: the Comprehensive Yeast Genome Database, Nucl. Acids Res. 33(Database issue) (2005) D364-D368.

[81] Y. Ho, A. Gruhler, A. Heilbut, G.D. Bader, L. Moore, S. Adams, A. Millar, P. Taylor, K. Bennett, K. Boutilier, L. Yang, C. Wolting, I. Donaldson, S. Schandorff, J. Shewnarane, M. Vo, J. Taggart, M. Goudreault, B. Muskat, C. Alfarano, D. Dewar, Z. Lin, K. Michalickova, A.R. Willems, H. Sassi, P.A. Nielsen, K.J. Rasmussen, J.R. Andersen, L.E. Johansen, L.H. Hansen, H. Jespersen, A. Podtelejnikov, E. Nielsen, J. Crawford, V. Poulsen, B.D. Sørensen, J. Matthiesen, R.C. Hendrickson, F. Gleeson, T. Pawson, M.F. Moran, D. Durocher, M. Mann, C.W. Hogue, D. Figeys, M. Tyers, Systematic identification of protein complexes in Saccharomyces cerevisiae by mass spectrometry, Nature 415 (2002) 2-5.

[82] A.C. Gavin, M. Bösche, R. Krause, P. Grandi, M. Marzioch, A. Bauer, J. Schultz, A.C. Gavin, M. Bösche, R. Krause, P. Grandi, M. Marzioch, A. Bauer, J. Schultz, J.M. Rick, A.M. Michon, C.M. Cruciat, M. Remor, C. Höfert, M. Schelder, M. Brajenovic, H. Ruffner, A. Merino, K. Klein, M. Hudak, D. Dickson, T. Rudi, V. Gnau, A. Bauch, S. Bastuck, B. Huhse, C. Leutwein, M.A. Heurtier, R.R. Copley, A. Edelmann, E. Querfurth, V. Rybin, G. Drewes, M. Raida, T. Bouwmeester, P. Bork, B. Seraphin, B. Kuster, G. Neubauer, G. Superti-Furga, Functional organization of the yeast proteome by systematic analysis of protein complexes, Nature 415 (2002) 141-147. 